\title{
CHAPTER 3.5.
}

\section{STERILE INSECT QUALITY CONTROL/ASSURANCE}

\author{
A. G. PARKER ${ }^{1}$, M. J. B. VREYSEN ${ }^{1}$, J. BOUYER ${ }^{1}$ AND \\ C. O. CALKINS ${ }^{2}$
}

${ }^{1}$ FAO/IAEA Agriculture and Biotechnology Laboratory, A-2444 Seibersdorf, Austria Email:a.g.parker@protonmail.com

${ }^{2}$ Deceased

\section{TABLE OF CONTENTS}

1. INTRODUCTION

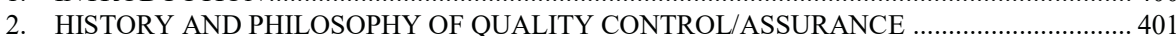

3. STRAIN DOMESTICATION, MAINTENANCE, AND REPLACEMENT ............................... 403

4. PARAMETERS OF QUALITY CONTROL .............................................................................. 405

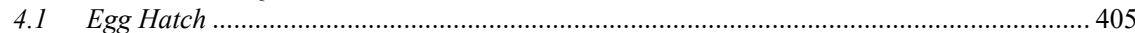

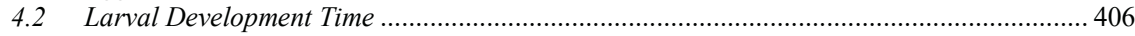

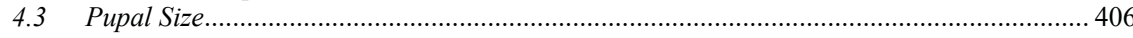

4.4. Percentage Adult Emergence ….............................................................................................. 406

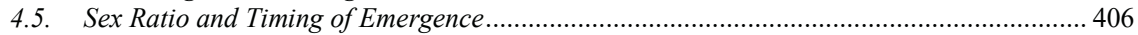

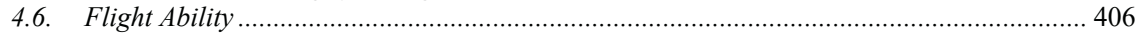

4.7. Pheromone Production and Response .............................................................................. 407

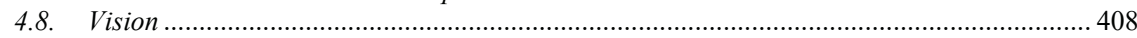

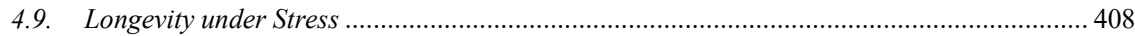

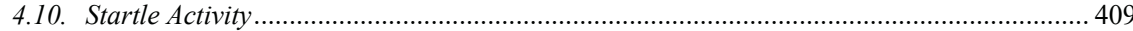

4.11. Mating Propensity, Compatibility, and Competitiveness .................................................... 409

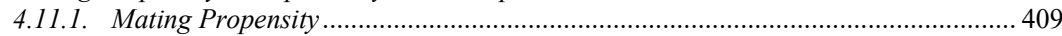

4.11.2. Mating Compatibility/Assortative Mating ............................................................ 410

4.11.3. Mating Competitiveness .................................................................................... 411

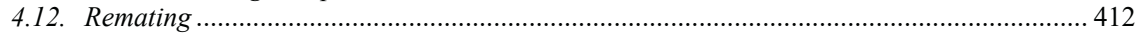

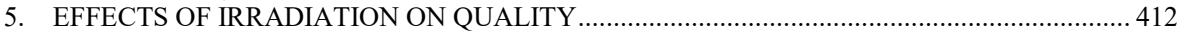

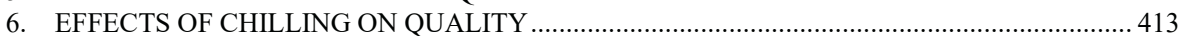

7. POST-SHIPMENT QUALITY CONTROL AT EMERGENCE AND RELEASE FACILITIES... 415

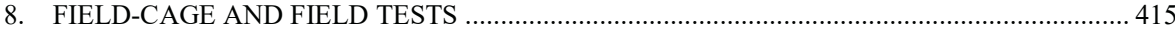

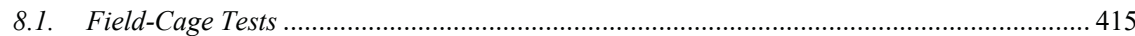

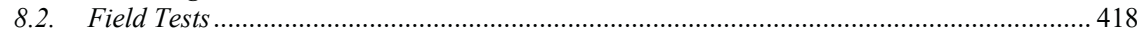

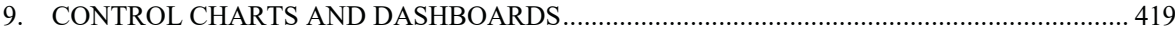

Pages 399-440

V. A. Dyck, J. Hendrichs and A. S. Robinson (eds.), Sterile Insect Technique. Principles and Practice in Area-Wide Integrated Pest Management. Second Edition.

Published with the permission of (C) 2021, US Government. CRC Press, Boca Raton, Florida, USA. 
10. IMPACT OF LOW-QUALITY INSECTS ON ERADICATION PROGRAMMES USING THE SIT

11. CHANGES IN INSECT BEHAVIOUR CAUSED BY LABORATORY REARING

12. REMEDIAL ACTIONS TO RESTORE EFFECTIVENESS OF REARED INSECTS

\section{SUMMARY}

The sterile insect technique (SIT) depends greatly on the production of good-quality sterile male insects that are released into target wild populations. Quality is controlled through a system of bioassays of quality parameters that reflect the insect's ability to survive natural enemies, interact with its environment, forage for food and water, and locate, mate and fertilize females of the target population. The system was developed by compartmentalizing the essential survival and mating behaviours of the species involved, and then developing a series of tests to confirm that these behavioural traits are present in the mass-reared insects. The system also has a feedback loop to correct problems in the production portion of the system before they become evident. Nevertheless, regular implementation of field or fieldcage tests under semi-natural conditions, where sterile males have to compete with wild males for wild females, is required to provide the ultimate confirmation that the sterile insects have the ability to fulfil their mission after release.

\section{INTRODUCTION}

A major concern of entomologists, and managers of area-wide integrated pest management (AW-IPM) programmes that integrate the sterile insect technique (SIT), is that released sterile males are adequate to fulfil the mission for which they were produced, i.e. that they compete well with wild males, and successfully mate and inseminate the targeted wild females. The components that are most important in such programmes include dispersal, survival under field conditions, location of mating arenas, courtship, mating, and sperm transfer (Koyama et al. 2004; Vreysen, this volume).

The ability of entomologists to evaluate and quantify the effectiveness of massreared sterilized insects in interactions with wild insects did not exist in the first decade of applying the SIT (Boller 2002). Initially, the effectiveness of released sterile insects was evaluated according to whether or not the SIT worked in the field. If it failed, managers were able to speculate only on what went wrong, or where and when the problem occurred.

In large suppression and eradication programmes using the SIT (Hendrichs, Vreysen et al., this volume), large numbers of insects must be reared for sterilization and release. Often the emphasis is on the numbers, and insect quality is overlooked or marginalized (Simmons et al. 2010; Itô et al., this volume). For many years, the SIT was considered as a "numbers game", i.e. if a programme began to fail, the remedy was to increase the sterile insect release rate. Only when a programme failed completely might the quality of the sterile insects be doubted, e.g. early in the New World screwworm Cochliomyia hominivorax (Coquerel) programme in the southwestern USA (Klassen et al., this volume; Vargas-Terán et al., this volume). The controversy surrounding the possible causes of this failure (Bush et al. 1976; LaChance et al. 1982) led to the adoption of regular strain renewal in the massrearing facility, and the development of a quality-control system to continuously 
monitor the insect colony using a series of behavioural and physiological tests to detect colony changes. This fostered the development of "quality control of massreared insects" as a recognized entomological discipline (Boller 1972).

This chapter discusses the history of the development of quality-control technology, the principles and philosophy of assessing insect quality, and the relative importance of the various parameters used to assess insect quality in the context of mass-rearing for the SIT. Quality control is most developed for various fruit fly species (FAO/IAEA/USDA 2019) and for tsetse flies (Mutika et al. 2001, 2002), but some advances have been made recently with Lepidoptera (Simmons et al. 2010; Vreysen et al. 2016) and mosquitoes (Balestrino et al. 2017). Quality control in rearing biological control agents is beyond the scope of this chapter.

\section{HISTORY AND PHILOSOPHY OF QUALITY CONTROL/ASSURANCE}

Scientists have long been aware that insects produced for laboratory purposes should be of a quality appropriate to the experimental system being tested. However, with the advent of mass-rearing and sterilization for the SIT, the quality of massproduced insects became even more important since appropriate behaviour in the field was now critical to the success of field programmes (Simmons et al. 2010).

Boller (2002) reviewed the history of the quality control of mass-reared insects. He divided this history into four distinct periods: (1) before 1969 - little concern about behavioural quality in rearing programmes, (2) 1969-1975 — a growing awareness of the ideas and concepts of quality control, (3) 1976-1979 international collaboration began, and prototypes of quality-control systems were initiated, and (4) 1980 to the present — finally the concept, and practical applications in most mass-rearing facilities, were generally accepted (Bernon and Leppla 1994; Bigler 1994; Leppla 2009).

The publication of an "idea book" on fruit fly quality control by Boller and Chambers (1977) is probably responsible for developing the subject of quality control into what is now recognized as a discipline of economic entomology. These authors were able to bring together the diverging schools of thought on quality control, and were able to combine the groups into a global Arthropod Mass Rearing and Quality Control Working Group (later renamed Mass Rearing and Quality Assurance (MRQA)) under the International Organization for Biological Control (IOBC). It had its first workshop in 1982, and subsequently a workshop has been held every three or four years (Leppla and De Clercq 2019). The proceedings of several of the workshops are available from MRQA/IOBC (2019) or in Leppla et al. (2002).

The terms "quality control" and "quality assurance" are closely related and often confused. The objective of quality control is to identify (and correct) defects in the finished product, while that of quality assurance is to prevent defects with a focus on the process used to make the product (Singh 2018). Therefore, quality control is reactive but quality assurance is proactive. The two terms are largely confused in the insect-rearing literature; few authors make a clear distinction, and most work to date is on quality control. Only a few rearing facilities have adopted quality assurance and achieved certification through the ISO 9000 standards (ISO 2019). Therefore, 
we will use the expression "quality control" throughout this chapter unless referring to specific work on quality assurance, and our use of "quality control" should be understood to include "quality assurance" unless otherwise indicated.

The fundamentals of quality control are basic to any manufacturing process. Rearing insects to fulfil a specific function is analogous to manufacturing a product. The principles and philosophy of quality control in the realm of manufacturing were established many years ago (Charbonneau and Webster 1978), and these same principles are adaptable today to the quality of mass-reared insects. These principles are described in an excellent book by Feigenbaum (2004), who defined total quality control as:

an effective system for integrating the quality-development, qualitymaintenance and quality-improvement efforts of the various groups in an organization so as to enable production and service at the most economical levels which allow for full consumer satisfaction.

Quality control is divided into three categories:

(1) Production quality control, where the inputs to rearing are addressed, including diet ingredients, equipment, etc.,

(2) Process quality control, measuring how things are done, such as diet preparation, environmental conditions, infestation rate, larval separation, pupal holding, irradiation dose, etc., and

(3) Product quality control, where the insects produced are evaluated for effectiveness in completing the purpose for which they are required.

This chapter concentrates on product quality control and some aspects of process control, while production and process control are covered in Parker, Mamai et al. (this volume).

The "control" in quality control is a management tool consisting of: (1) setting quality standards, (2) appraising conformance to these standards, (3) acting when the standards are breached, and (4) planning for improvements in the standards (Barnes et al. 2015). The difference between mass-producing insects and rearing small colonies for laboratory experiments is in the product rather than the process. In other words, the "bottom line" of a mass-rearing programme is the performance of the released insects in the field (FAO/IAEA 1992).

While the factors affecting product quality are both technological and human, the human factors, involving operators, section leaders, and other personnel, are by far the most important, and the problems most likely to occur are often related to the human factors. The purpose of a quality-control programme is to identify and address the factors leading to low quality during the rearing process, instead of focusing on enhancing low-quality insects after they have been reared (Pereira et al., this volume). Such a programme results in improvements in product quality and employee morale, and reductions in production costs and production "bottlenecks". It also provides improved inspection methods, definite schedules for preventive maintenance, and a factual basis for standards during the rearing process.

The development of a functioning quality-control programme depends on a continuous chain of responsibility for quality through all the workers. To achieve this, responsibilities for quality should be assigned to all key personnel in the rearing facility. Certain workers should be assigned to evaluate insect quality using 
scheduled bioassays; their only responsibility should be product quality, and they must be answerable only to the programme manager. These people serve as the "eyes and ears" of the programme manager; they must never be answerable to the rearing manager. "Control" in quality control is achieved when there is constructive feedback, from the quality-control workers through the programme manager, on activities and factors that may be responsible for the lack of quality.

Quality-control procedures both incur costs and provide benefits. The costs are in the appraisal costs of evaluating inputs, processes and product quality, while benefits accrue from savings associated with avoiding: (1) defects during the rearing process, (2) internal failure costs caused by defective equipment, materials, or substandard rearing ingredients, and (3) external failure costs caused by allowing defective products to reach a customer, e. g. insects that do not survive under natural conditions, are not competitive with wild males, are incompatible with the target population, or were inappropriately irradiated.

\section{STRAIN DOMESTICATION, MAINTENANCE, AND REPLACEMENT}

Over time, under artificial rearing conditions, important behavioural and physiological traits undergo change characterized by Ochieng'-Odero (1994) as acclimatization, selection, and domestication. Examples of such affected traits are: fecundity, preoviposition period, courtship song, flight, oviposition, rate of development, production of pheromone, response to pheromone, eye morphology, visual sensitivity, metabolic rate, and resistance to stress (Mangan 1992). The potentially negative impact of changes resulting from this domestication process was discussed by Boller (1972), Rössler (1975a, b), Huettel (1976), Mackauer (1976), Van Keymeulen et al. (1981), Shimoji and Miyatake (2002), and Caprio (2009).

When insects are brought into the laboratory to initiate mass-rearing, the conditions to which they are subjected are very different from those to which the species is adapted in the field. These conditions exert different selection pressures on the individuals brought from the field to initiate a colony, selecting a small subset of the population with a reproductive advantage under the new conditions, potentially creating a genetic "bottleneck". The drive to reproduce may overcome some of the inappropriate environmental aspects, but the accumulated changes in courtship and other behaviours resulting from the selection process may be detrimental once the insect is released back into the field, reducing survival and mating competitiveness with wild insects.

The constraints of mass-production of insects can lead to selection for rapid larval development, short pupal period, early sexual maturity, reduced pheromone production, abbreviated courtship behaviour, and early fecundity (Miyatake 1993, 1998a, b; Miyatake and Yamagishi 1999; Cayol 2000). Changes in mating behaviour will reduce the competitiveness of the reared male insects (Miyatake and Shimizu 1999), but other changes caused by mass-rearing may be linked to other detrimental changes, such as reduced predator avoidance during male courtship (Hendrichs et al. 1994; Hendrichs and Hendrichs 1998). In the melon fly Zeugodacus cucurbitae (Coquillett), changes in the circadian rhythm and time of mating can be linked to selection for early mating (Miyatake 2002; Miyatake et al. 
2002) and rapid development (Miyatake 1996, 1997a), changes in longevity to early fecundity (Miyatake 1997b), and mating success to rearing density (Miyatake and Haraguchi 1996). However, Liedo et al. (2007) showed that quite small changes in adult colony rearing conditions may improve quality.

To produce large numbers of insects, an appropriate artificial diet is usually required (Lees et al., this volume; Parker, Mamai et al., this volume); often this diet has already been developed and proven adequate for the development of immature stages. However, when a large number of eggs is placed on a limited amount of diet, the situation may change. Waste products from larvae can create an intolerable situation for the insects and/or workers. Metabolic heat could raise the temperature, resulting in too-rapid development. The nutritional value of the diet may change. In any case, selection occurs for individuals that can tolerate these conditions. Pupal handling and storage also create conditions for selection. Each of these parameters can cause a genetic "bottleneck" that severely limits the number of individuals that survive the first few generations. As each subsequent generation becomes better adapted to the rearing conditions, a larger proportion of insects survives.

Severe "bottlenecking" does not always result in a permanently limited gene pool, but the gene frequency may change. When the population is increased substantially, the number of mutations also increases. Nei et al. (1975) speculated that, when populations expand, genetic diversity increases through mutations. The reduction in average heterozygosity per locus depends on the size of the bottleneck, and on the rate of population growth. If, after going through even an extremely small "bottleneck", the population size increases rapidly, there may be significant recovery of heterozygosity. That does not mean that the population returns to the identical diversity of the original gene pool. The western spruce budworm Choristoneura occidentalis Freeman, reared for 88 generations in a laboratory, lost 15 alleles, but the quality of the insects (in terms of size, fecundity, vigour, longevity, and disease resistance) was adequate for research purposes (Stock and Robertson 1982); the researchers made no mention of interaction with wild populations. Vale et al. (1976) reported no changes in activity or behaviour of the tsetse flies Glossina morsitans Westwood and Glossina pallidipes Austen due to laboratory rearing or artificial in vitro feeding.

In an AW-IPM programme that applies the SIT, the parameters necessary for the reared and sterilized males to be effective are: successful emergence and good field survival to the age of sexual maturity, sufficient mobility to find food, shelter, and wild females in a mating arena, swarming sites or other sites, mating competitiveness with the wild male for the wild female, mating compatibility with a wild female, successful transfer of sperm and accessory gland fluids, and adequate mobility and survival of the sperm.

To ensure that a rearing procedure is producing insects with these necessary traits, it is essential to have a system of quality-control tests that measures these parameters, as well as overall compatibility and competitiveness with the wild target population. The tests must be conducted on a regular basis so that the rearing process maintains the product quality in the long term (Parker, Mamai et al., this volume). If detrimental changes in insects begin to appear, a feedback loop to the rearing system is necessary so that the shortcoming can be identified, the cause determined, and the problem corrected (Calkins et al. 1988; FAO/IAEA/USDA 
2019). A filter rearing system is usually used to maintain the stability of genetic sexing strains, from which the normal mass-rearing colony is derived (Franz et al., this volume; Parker, Mamai et al., this volume). However, the same concept can be used to provide a means to control the selection pressure on the "mother" stock used for the colony while avoiding many of the worst traits from the pressure of massrearing (Fisher and Caceres 2000). A further step in this direction is the application of a "pre-filter" - a small adult colony held under semi-natural situations at low densities, e.g. a greenhouse within the mass-rearing facility, where it is exposed to variable conditions, natural-light cycles, hosts and predators to maintain as long as possible the viability of a newly introduced mother colony - instead of regularly bringing in new colonies that rapidly lose, in a few generations, their natural characteristics (Hendrichs and Robinson, this volume).

Strain replacement becomes essential when the properties of the reared strain become too different from the target population, and corrective measures are no longer effective. Replacing a strain can be a major task, takes considerable time, and also involves substantial cost. Newly collected field material may take several generations to adapt to colony rearing, with the colony stabilizing after about five generations (Bartlett 1984). If this involves an obligatory diapause, the time investment is clearly large. In the case of tsetse flies, the colonization of $G$. pallidipes in Ethiopia required more than 60000 wild females over a period of 14 months to establish a viable colony, representing 4 or 5 generations of adaptation (Alemu et al. 2007).

Another potential hazard is the contamination of the new strain by insect pathogens such as densovirus (Carlson et al. 2006), hytrosavirus (Abd-Alla et al. 2013) or even human pathogens including arboviruses such as dengue that can be transmitted vertically in the case of a colony of mosquitoes (Buckner et al. 2013; Abd-Alla et al., this volume).

\section{PARAMETERS OF QUALITY CONTROL}

Product quality control covers the biological parameters of the reared insects. While the emphasis in this chapter will be on product control, some aspects of process control are also considered. Measurements for different groups of insects may involve different procedures. Information relating to tephritid fruit flies for most of the following sections can be found in FAO/IAEA/USDA (2019), most of which can be adapted to other insect groups, e.g. FAO/IAEA (2006).

\subsection{Egg Hatch}

Changes in egg hatch or eclosion may indicate problems with mating in the colony, insufficient sperm quality or quantity in the males, inadequate sperm transfer to the females, insufficient sperm motility or infection with a pathogen. Samples of eggs should be monitored regularly for hatch rate, and also to ensure correct larval density in the diet. 


\subsection{Larval Development Time}

As observed previously, changes in development time can be related to inadequate temperatures in the larval diet resulting from an incorrect egg seeding density, diet composition or rearing environment, as well as to changes in courtship behaviour. Development period should be monitored, and selection for rapid development avoided.

\subsection{Pupal Size}

Pupal size is a good indicator of larval diet quality, rearing density, and any contamination or infestation problems. It is also an indirect measurement of reserves accumulated, affecting the longevity parameter under the stress test (section 4.9.). Pupal size is measured either by minimum diameter or weight. In some insects adult size, e.g. wing length in mosquitoes, is also used.

\subsection{Percentage Adult Emergence}

The percentage of insects that emerges successfully, and may be affected by larval nutrition (pupal energy reserve), excessive temperature during the rearing and pupalholding periods, and inappropriate relative humidity. Mishandling of pupae, such as excessive jarring, tumbling at early pupal stages, and excessive radiation dose may also influence percentage emergence and flight capacity.

\subsection{Sex Ratio and Timing of Emergence}

Sex ratio may be affected by poor pupal-holding conditions, or in the case of a sexing strain that is based on a temperature-sensitive lethal (tsl) mutation, inappropriate temperature at any stage in the rearing. Timing of emergence indicates the uniformity of pupal age (pupal collection and handling control), and may warn of selection for inappropriate accelerated development. Uniformity of pupal age at irradiation is also a critical determinant of the extent to which exposure to radiation procedures affects the quality of flies (FAO/IAEA/USDA 2019).

\subsection{Flight Ability}

Released sterile insects need to be sufficiently mobile and have adequate dispersal capabilities to reach, in a timely fashion, all the ecological niches that are occupied by the wild insects (Vreysen et al. 2016). Therefore, the ability of sterile insects to fly, after having been released in the field, is an essential attribute. Those insects that cannot fly to shelter or to food, or cannot reach the pheromone-calling or mating sites, are lost to the programme.

"Percent flight" is the percentage of insects that can fly, based on the number of pupae put into an emergence/flight tube. This may also be corrected for percentage emergence, a parameter called "absolute fliers", and which determines the number of adults that can be released (FAO/IAEA/USDA 2019). 
Reductions in flight, dispersal, and survivability due to rearing and/or irradiation have been noted by a large number of researchers, e.g. Dame et al. (1969), Rajagopalan et al. (1973), Sharp (1976), Nelson and Milby (1980), Nakamori and Soemori (1981), and Smith et al. (1981). Little and Cunningham (1978), Sharp et al. (1980), Little et al. (1981), and Sharp and Little (1982) found that sifting of fruit fly pupae at a critical stage in their development was the reason that indirect flight muscles did not insert properly into the cuticle of the exoskeleton during pupal development. This created the "droopy-wing syndrome" in which various degrees of droopy wings resulted in non-flying flies (Little and Cunningham 1978).

Knowledge about the mobility and dispersal characteristics of released insects is essential for developing and designing appropriate release strategies (Vreysen, this volume). A simple quality-control test suitable for routine testing, the flight-ability test, measures the ability of the insects to fly out of a restricted space (Carpenter et al. 2012; FAO/IAEA/USDA 2019; Seck et al. 2015; Balestrino et al. 2017; Culbert et al. 2018; Lees et al., this volume). In the last decade, several more elaborate methods have been developed to assess flight ability of mass-reared Lepidoptera, e.g. flight mills (Zhang et al. 2016), wind tunnels (Stringer et al. 2013), and flight assessment cages (Saour 2016), that would be appropriate for periodic testing.

Recent developments in machine vision, to record and analyse insect behaviour, would offer the opportunity to quantify important quality factors such as flight ability, mating propensity, and competitiveness. The flight tracks of irradiated male light brown apple moths Epiphyas postvittana (Walker) in a wind tunnel responding towards a calling female were different from those of untreated moths. This approach is likely to be amenable to automation, and could potentially be used in routine quality control (Suckling et al. 2011).

\subsection{Pheromone Production and Response}

For certain insect groups such as fruit flies and Lepidoptera, pheromone emission and response are the earliest interactions that sterile males have with wild females. For fruit flies, the response of wild females to pheromone-calling wild or sterile males can be compared using the pheromone compatibility test carried out in field cages (FAO/IAEA/USDA 2019). For Lepidoptera, the response of released males to synthetic pheromone can be measured in a wind tunnel (Stringer et al. 2013) and to calling females in mating cages (Saour 2016) or on mating tables (Snow et al. 1976; Flint and Merkle 1984; McBrien and Judd 1996). A commercial insect-locomotionactivity meter was used to assess responses of wild and irradiated E. postvittana towards repeatable pheromone pulses. Non-irradiated males responded towards the pheromones significantly better than irradiated males. A high-temperature shock did not change the response of the non-irradiated moths, but it slightly diminished the response of irradiated moths. The system showed potential to assess routinely the quality of mass-reared moths, and might be suitable for factory-scale quality control (Brown et al. 2016).

Continuous laboratory rearing may create subtle changes in components of a pheromone emitted by a sterile male (or female), rendering it unattractive to a wild female (or male) (Minks 1971), but this does not always happen (Richmond and 
Berisford 1980; Sower et al. 1973); in the case of field-caged males of the Mediterranean fruit fly Ceratitis capitata (Wiedemann), more wild females were attracted to sterile males than wild males. Close examination of the behaviour of the field-caged males revealed that sterile males "pheromone-called" more frequently, and for longer periods of time, than wild males (C. O. Calkins and T. R. Ashley, unpublished data); this may appear to be an advantage, but actually exposes sterile males to more predation attacks (section 4.10.) (Burk 1982; Hendrichs and Hendrichs 1998).

Protein feeding by adult male Mediterranean fruit flies enhances pheromone production and hence competitiveness (Kaspi and Yuval 2000; Shelly et al. 2002; Yuval et al. 2002, 2007). Protein feeding by males, together with size, also enhances post-copulatory sexual selection (Taylor and Yuval 1999). Therefore, providing sterile males with pre-release access to protein can enhance their field performance (Pereira et al., this volume).

Some insects require specific nutrients and semiochemicals to be able to synthesize their pheromone; supplying this to adults during their maturation can improve field performance, and reduce time spent by the released insects searching for this component in the field (Ji et al. 2013; Obra and Resilva 2013; Tan and Tan 2013; Haq et al. 2014, 2015, 2016; Pereira et al., this volume).

\subsection{Vision}

Agee and Park (1975) developed the use of an electroretinogram to measure the quality of the vision of fruit flies; irradiation debilitated both the sensitivity and spectral accommodation. Rössler (1980) discovered that the sexual competitiveness of Mediterranean fruit fly males, possessing an apricot eye-colour mutant, was reduced. Using the apricot-eye strain for mating and acoustical tests, it was observed that, during courtship, a mutant male could not follow closely the wing waving of a normal female, resulting in the female rejecting the male's advances.

Visual impairment was also observed in mass-reared New World screwworms (Bush et al. 1976), necessitating strain replacement (Klassen et al., this volume).

\subsection{Longevity under Stress}

In many insect species, the nutrient reserves acquired during the larval stage and carried through the pupal stage affect the longevity of the adult stage. The longevity/stress test, often related to pupal size, measures the percentage of adults that survives for a set time period, depending on species, without food or water (Orozco-Dávila et al. 1983; Ashley 1987; Mutika et al. 2002). Since this test produces stress, it is indicative of the amount of nutritional reserves present when adults emerge. It has recently been adopted as a quality-control parameter in tsetse flies (Seck et al. 2015).

While protein feeding improves pheromone production in Mediterranean fruit flies, it also reduces survival when they face starvation (Taylor and Yuval 1999). However, Maor et al. (2004) demonstrated that Mediterranean fruit flies fed on protein are successful at exploiting both protein and carbohydrate resources in the 
field, and their inability to overcome starvation is not a concern. Yuval et al. (2007) reached the same conclusion, stating that it may be better to release short-lived flies that are highly competitive instead of long-lived sexually ineffective ones.

\subsection{Startle Activity}

A common problem in laboratory-reared insects is the loss of irritability. Massrearing conditions apparently select inadvertently for insects that, to maximize their fitness, can afford under the protected but very dense colony environment to ignore any movements in their immediate surroundings. As a result, they also disregard any potential dangers after being released in the field, and thus are much more susceptible than wild insects to many of the predators they will encounter (Hendrichs and Hendrichs 1998). The "startle test", developed by Boller et al. (1981), measures levels of irritability, and this or a similar test that measures capacity for predator evasion (Hendrichs et al. 2007; Dor et al. 2014; GonzálezLópez et al. 2016; Dor and Liedo 2018; Rathnayake et al. 2019) could be used to select for increased irritability. The level of irritability appears to be inherited genetically (C. O. Calkins, unpublished data), and hence a proper management of the mother colony could probably maintain some degree of irritability.

\subsection{Mating Propensity, Compatibility, and Competitiveness}

\subsubsection{Mating Propensity}

Mating speed or mating virility is one indicator of fitness (Pendlebury and Kidwell 1974; Lance and McInnis, this volume). This test measures the propensity or willingness of mass-reared sterilized males to mate with virgin females. This is appropriate only for male-choice mating systems; it provides no information for female-choice systems (Lance and McInnis, this volume).

Mating propensity presumably measures, by the use of the mating index, how "eager" the sterile males are to mate. However, as this test is usually conducted in the laboratory with reared males and females, results are often not representative of laboratory male performance when exposed to wild females in the field. This is confirmed by the fact that laboratory-reared males usually have a higher mating index than wild males.

Rapid matings tend to be controlled by the male genotype, while the female genotype may assume importance in slower matings (Parsons 1974). Therefore, for female-choice mating systems, this test is often misleading because mating speed largely reflects the fact that males, selected under extremely high-density adultcolony conditions (where most females become receptive at the same time, and thus a 1:1 operational sex ratio to courting males prevails), obtain rapid matings without going through the proper courtship sequence. These males are often rejected by wild females while attempting to court them in leks under natural conditions (Briceño and Eberhard 1998; Hendrichs et al. 2002). 


\subsubsection{Mating Compatibility/Assortative Mating}

The ability of reared sterilized males to compete successfully in mating with the males of the target population is crucial for the SIT. Reduced competitiveness can arise from problems in rearing, irradiation or handling, but also from inherent incompatibility between different strains. For example, the Mediterranean fruit fly arrived in southern Europe from West Africa via the Cape Verde Islands in the 1700s, while it reached Hawaii from East Africa via Australia in the late 1800s, and the populations in South America probably arrived from West Africa. The resulting isolation of these populations might allow the accumulation of changes, which will eventually lead to reproductive isolation and incipient speciation. Some evidence of reproductive isolation in island situations has been found (Hibino and Iwahashi 1991; McInnis et al. 1996; Miyatake 1998a), but an extensive comparison of Mediterranean fruit fly strains from around the world with the main mass-rearing strains showed no significant mating barriers (Cayol et al. 1999, 2002), indicating that in this species any mass-reared strain can be used against any wild population.

Similar results, i.e. no evidence of mating barriers, were obtained with codling moth populations from around the world (Taret et al. 2010), and with olive fruit fly Bactrocera oleae (Rossi) populations from the Mediterranean basin (Ahmad et al. 2018). The same result was observed between strains of $G$. palpalis gambiensis originating from Burkina Faso, Mali, and Senegal (Mutika et al. 2013), even though the strain from Senegal, for example, displayed substantial ecological and genetic divergence from the other strains (Bouyer et al. 2010; De Meeûs et al. 2015).

Reisen et al. (1980) detected assortative mating in releases of Culex tritaeniorhynchus Giles, as did Raulston et al. (1976) with the tobacco budworm Heliothis virescens (F.). The latter was caused by a change in the temporal mating period of the laboratory-reared population which initiated courtship $2 \mathrm{~h}$ earlier than the wild population. Zervas and Economopoulos (1982) observed that laboratoryreared olive fruit flies also began to mate $2 \mathrm{~h}$ before wild flies, although this was not observed in field-cage studies using newly established colonies (Ahmad et al. 2018). Wong et al. (1982) noted assortative mating between laboratory-reared and wild oriental fruit flies Bactrocera dorsalis (Hendel). On the other hand, Spates and Hightower (1967) found that New World screwworm males became sexually more aggressive when reared in the laboratory. However, assortative mating in Anastrepha fraterculus (Wiedemann) led to the realization that this widespread South and Central American species is actually a complex of sibling species (Cáceres et al. 2009; Segura et al. 2011; Hernández-Ortiz et al. 2012; Devescovi et al. 2014).

Differential mating preferences of wild and released sterile insects will reduce the efficacy of the SIT component in AW-IPM programmes (Hibino and Iwahashi 1991), but these negative impacts have often been underestimated (Vreysen et al. 2006). It is known that selective mating occurs between colonized New World screwworm strains of different age, with males from strains that have been cultured for many generations being non-selective in mating with old-line or new-line females, but new-line males copulated more readily with females from newly colonized strains than with females from older strains (Spates and Hightower 1970). This asymmetric mating isolation between the behaviours of old and new screwworm strains has been associated with reduced female contact-pheromone 
activity (Hammack 1987), but its relevance and effects on the efficiency of SIT projects have never been researched properly in the field. Vreysen et al. (2006) present models that examine this effect, and it was demonstrated clearly that, for older screwworm strains, a doubling in the number of sterile male insects released per surface area is required to obtain a suppression effect similar to that when no asymmetric mating isolation is present. Consequently, the discriminatory behaviour of wild screwworm males against sterile females has significant economic implications.

\subsubsection{Mating Competitiveness}

In-depth knowledge about the mating behaviour of the target insect, and the factors that could impair this behaviour, is indispensable for improving the performance of the sterile insects - to increase the overall efficiency of the SIT, and hence to reduce its cost (Hendrichs et al. 2002). The size of males can also be an indirect indicator of mating competitiveness. It affects mating success in the Caribbean fruit fly Anastrepha suspensa (Loew) (Burk and Webb 1983) and the Mediterranean fruit fly (Churchill-Stanland et al. 1986, 1987; Bloem et al. 1993a, b, c; Economopoulos et al. 1993; Orozco and Lopez 1993). A larger male is more competitive against rival males, and females tend to select larger males over smaller ones, but Hunt et al. (2002) found an effect of size on pheromone calling but not on overall mating success. In field releases, larger males disperse farther and live longer than smaller males (Bloem et al. 1994) (section 4.9.). Pupal weight is a good indicator of adult size, and Mediterranean fruit fly programmes (to comply with quality standards) require that late-stage pupae should weigh about $7 \mathrm{mg}$. In New World screwworm programmes, late-pupal weight should not fall below $44 \mathrm{mg}$.

However, in Aedes aegypti (L.) mosquitoes, it was demonstrated that large females showed no evidence of a mating preference, whereas small males were relatively more successful than large males when mating with small females, exhibiting an advantage of around 20-25\% (Callahan et al. 2018). This result shows that size might matter, and should be monitored in mosquito SIT programmes, particularly when considering that laboratory-reared mosquitoes can often be larger than their wild counterparts (which experience more competition for food in their larval habitats, especially in the case of Aedes species that exploit micro-habitats).

Laboratory bioassays often do not indicate accurately the field performance of reared insects (Katsoyannos et al. 1999). Quality-control tests (that usually are more appropriately carried out under semi-natural conditions in field cages containing vegetation) are: pheromone attractiveness, mating compatibility, and mating competitiveness (Zapien et al. 1983; Cayol et al. 1999, 2002; FAO/IAEA/USDA 2019). It has been recommended that, at least once a year, AW-IPM programmes releasing sterile insects obtain insects from the field population being targeted, and compare them with mass-reared insects in field cages that permit as large a range of natural behaviours as possible, including female choice (FAO/IAEA/USDA 2019; Lance and McInnis, this volume; Parker, Mamai et al., this volume). Field-cage and field tests are discussed below (section 8.). 


\subsection{Remating}

A further important component of mating behaviour for the SIT is remating by wild females (Lance and McInnis, this volume; Whitten and Mahon, this volume). Female monogamy is not required for the SIT, but if there is a differential rate of remating by females first mated to a sterile or a wild male, or there is sperm selection following multiple matings, there will be an effect on the SIT (Bonizzoni et al. 2007; Pérez-Staples et al. 2013).

Remating may be controlled by factors transferred by the male during copulation; if the mass-reared males do not transfer the necessary factors, the incidence of remating may rise differentially (Jang 2002; Vera et al. 2002). This may be measured in an extension to the field-cage compatibility/competitiveness tests listed above. The females from pairs collected in the compatibility/competitiveness test are marked according to the male with which they first mated, and the field-cage test repeated on subsequent days. Remating pairs are then scored, and the results examined for evidence of differential remating (McInnis et al. 2002).

Multiple mating of female insects is common in Lepidoptera; this was recently confirmed with Eldana saccharina Walker under controlled laboratory conditions. The multiple-mating potential of both males and females might have consequences for obtaining adequate sterile to wild male overflooding ratios (Walton and Conlong 2016a; Barclay, this volume). Multiple mating is also common for females of the cluster caterpillar Spodoptera litura (F.); a study on sperm-use patterns revealed that females preferentially use the sperm of the last male to mate. In addition, female mating success, remating propensity, and fertility were significantly influenced by mating sequences that included irradiated males (Seth et al. 2016). Multiple mating is not uncommon in insects, e.g. fruit flies, tsetse flies, and mosquitoes. Barclay (this volume) discussed modelling the impact of multiple mating on the SIT.

\section{EFFECTS OF IRRADIATION ON QUALITY}

An essential step in the SIT is the induction of sterility. In many insect groups, irradiation results in a reduction in competitiveness (Bakri et al., this volume), and much recent work has been aimed at reducing this negative effect.

The timing of irradiation can be adjusted to reduce the effects without creating logistical and handling problems. Normally, the least amount of damage to adult males is caused when irradiation is carried out shortly after emergence, but the problem of irradiating large numbers of adult insects at one time is often challenging; therefore, usually pupae are irradiated as pharate adults shortly before emergence (Bakri et al., this volume). For various fruit flies, pupal development is monitored by eye colour to determine the optimal timing for irradiation (Ruhm and Calkins 1981; Resilva and Pereira 2014; Resilva et al. 2019).

Irradiation in air creates free radicals that are detrimental to the quality of insects. When oxygen is excluded by flooding the containers with nitrogen, this problem is reduced in fruit flies and codling moths (Ashraf et al. 1975; Robinson 1975). Later, it was discovered that when containers of fruit fly pupae were sealed, pupal metabolism quickly exhausted the oxygen and produced carbon dioxide, resulting in 
similar protection (Ohinata et al. 1977; Bakri et al., this volume). The effects of hypoxia have also been investigated in several other insects (Vreysen and Van Der Vloedt 1995; Hallman 2005; López-Martínez et al. 2014, 2016; Yamada et al. 2019).

In many insect species, females become $100 \%$ sterile at lower doses than males. Attempts to attain $100 \%$ sterility in males usually reduce quality; often it will be better to reduce the dose so as to obtain a better induction of sterility in the field females through more competitive males (Hooper 1972; Toledo et al. 2004; Parker and Mehta 2007).

In Lepidoptera, the higher radiation sensitivity of females has been exploited to adopt an $F_{1}$ sterility or inherited sterility (IS) strategy; very high radiation doses are required to induce dominant lethal mutations in Lepidoptera (Proverbs and Newton 1962; Blomefield et al. 2010; Soopaya et al. 2011; Cagnotti et al. 2012, 2016; Jang et al. 2012; Saour 2014; Fu et al. 2016; López-Martínez et al. 2016; Walton and Conlong 2016b; Chakroun et al. 2017; Marec et al., this volume). In these insects, a lower dose that partially sterilizes the males but completely sterilizes the females can be employed to induce sterility in the subsequent generation. A higher percentage of male moths exposed to substerilizing doses respond to virgin females than those treated with higher doses (Bloem et al. 2001; Simmons et al., this volume).

Irradiation can affect various quality parameters to varying degrees, including survival (Vreysen and Van Der Vloedt 1995; Opiyo 2001), mating competitiveness and seminal-fluid transfer (Mutika et al. 2002), flight ability (Stringer et al. 2013; Saour 2016; Zhang et al. 2016), and production of and response to pheromones (McGovern et al. 1975; White and Hutt 1975). Both dose fractionation (Vreysen and Van Der Vloedt 1995; Kumano et al. 2011a, b) and hypoxia (Ohinata et al. 1977; Vreysen and Van Der Vloedt 1995; Hallman 2005; López-Martínez et al. 2014, 2016; Yamada et al. 2019; Bakri et al., this volume) may reduce these negative impacts.

\section{EFFECTS OF CHILLING ON QUALITY}

Before irradiation and prior to shipping, pupae are often chilled to lower their metabolic rate. Therefore, understanding tolerance of pest insects to thermal extremes is essential to ensure optimal insect quality after shipment; tolerance traits can provide insights into constraints on their activity and survival. Long-distance shipments of irradiated Mediterranean fruit fly pupae (either chilled or not chilled) were compared by Brazzel et al. (1986). Pupae shipped for $18 \mathrm{~h}$ in hypoxia averaged $77 \%$ emergence and $70 \%$ fliers, but those shipped in hypoxia in chilled boxes averaged $82 \%$ emergence and $76 \%$ fliers. Pupae shipped for $40 \mathrm{~h}$ in bottles in hypoxia averaged $48 \%$ emergence and $34 \%$ fliers, but those in hypoxia and chilled boxes averaged $73 \%$ emergence and $62 \%$ fliers.

Prolonged chilling (exceeding $26 \mathrm{~h}$ ) can be detrimental to fly emergence at the release point, but not as detrimental as hypoxia with no chilling (FAO/IAEA 2017a). Serghiou (1977) discovered that the competitiveness of irradiated sterile Mediterranean fruit flies decreased as their exposure to chilling increased, but chilling did not have an adverse effect on survival. 
In view of the need to synchronize releases of sterile male tsetse flies ( $G$. pallidipes), Mutika et al. (2002) stored pupae at various low temperatures, and found that no significant differences in emergence, survival without a blood meal, or insemination capacity occurred. In fact, male adults emerged from pupae that had been stored at $15^{\circ} \mathrm{C}$ started mating more quickly, and formed more mating pairs, than the controls (stored at room temperature). However, if adult males were chilled (and then removed from the low-temperature container for testing), insemination capacity was reduced, and mortality was $10-32 \%$. Later, it was observed that storing the pupae at $4{ }^{\circ} \mathrm{C}$ actually reduced the emergence rate significantly, down to $76.1 \pm 13.2 \%$ when they were chilled for $1 \mathrm{~d}$ in the source insectary before transport to Senegal, and to $72.2 \pm 14.3 \%$ when they were chilled for $2 \mathrm{~d}$ (Pagabeleguem et al. 2015).

In Anopheles arabiensis Patton, chilling the males at $4-10^{\circ} \mathrm{C}$ for $24 \mathrm{~h}$ did not have any significant negative effect on their survival (Culbert et al. 2017). Also, in Ae aegypti, chilling males for $2 \mathrm{~h}$ at $4-10^{\circ} \mathrm{C}$ did not reduce the survival rate significantly, but chilling them at $0^{\circ} \mathrm{C}$ for the same duration reduced their survival significantly. Moreover, the full insemination rate of females by the treated males, as well as their flight ability, declined from exposure to temperatures of $8^{\circ} \mathrm{C}$ and lower (Culbert et al. 2018).

Insect thermal limits may vary with microclimatic fluctuations, and may be influenced by biotic or abiotic factors. Chill-coma temperature (CTmin) and critical thermal maximum (CTmax) were significantly different for E. saccharina moths collected from two host plant species, i.e. sugar cane and papyrus. However, the lower lethal temperature (LLT) of these moths, and the freezing temperature of the pupae, did not vary with the host plant species. Therefore, host plants may strongly mediate the lower critical thermal limits, but not necessarily the LLT or freezing temperatures (Kleynhans et al. 2014).

Male and female laboratory-reared E. saccharina were more heat tolerant than wild moths, but the latter were more cold tolerant than their laboratory-reared counterparts. Irradiation had a deleterious effect on the CTmax and the CTmin. Moths irradiated with a lower dose were more heat and cold tolerant than those irradiated with a higher dose, highlighting again the importance of treating lepidopterans with a lower dose rather than with the full sterilizing dose (Mudavanhu et al. 2014).

False codling moths Thaumatotibia leucotreta (Meyrick) exposed to $-4.5^{\circ} \mathrm{C}$ for 2 $\mathrm{h}$ or to $-0.5^{\circ} \mathrm{C}$ for $10 \mathrm{~h}$ had a $50 \%$ probability of survival, and their low-temperature tolerance was not affected by gender or adult age. Only limited evidence for cold hardening was found; survival did not increase after exposure to non-lethal, low- and high-temperature pre-treatments (Stotter and Terblanche 2009). The colony was found to be adequate under most temperature conditions, but not during the coldest months (Boersma and Carpenter 2016); it is proposed to develop a second, coldadapted strain for release during the winter months.

Recapture rates of codling moths (that had been acclimated to low temperatures) were significantly greater under cooler conditions in the wild than either warmacclimated or control moths. However, improvements in low-temperature performance of cold-acclimated moths came at a cost to performance under warmer conditions. Conversely, moths acclimated to higher temperatures performed better 
under warmer ambient conditions in the field when compared with cold-acclimated moths or control moths. Laboratory data matched field results, indicating that assessment of thermal activity of codling moths in the laboratory may also apply to their field performance (Chidawanyika and Terblanche 2011).

Rearing codling moths through diapause improved their competitiveness in orchards (Dyck 2010), but their radio-sensitivity was similar to that of moths reared under non-diapause conditions (Carpenter et al. 2010).

\section{POST-SHIPMENT QUALITY CONTROL AT EMERGENCE AND RELEASE FACILITIES}

In operational programmes covering large areas (or when shipping sterile insects to transnational customers), it may be necessary for efficient operation to have one or more emergence and release facilities separate from the rearing facility that are close to the release sites (Dowell et al., this volume). Pupae (or chilled adults) can be shipped in bulk from the rearing facility to the emergence and release facility (FAO/IAEA 2017a) where they can be held for emergence and maturation, and be supplied with appropriate environmental conditions, diet components and other treatments to condition them for release (Chidawanyika and Terblanche 2011; Ji et al. 2013; Obra and Resilva 2013; Tan and Tan 2013; Haq et al. 2014, 2015, 2016; Dowell et al., this volume; Pereira et al. this volume).

The FAO/IAEA/USDA (2019) manual (sections 6 and 7) provides a number of tests for process and product quality control for emergence and release facilities receiving shipments of sterile insects. This international standardization of postshipment quality-control tests allows the supplier and receiver to compare the quality of commercial and transboundary shipments of sterile insects.

\section{FIELD-CAGE AND FIELD TESTS}

\subsection{Field-Cage Tests}

As noted above, laboratory tests of competitiveness or compatibility generally do not reliably indicate the performance in the field (Katsoyannos et al. 1999; Itô et al., this volume; Vreysen, this volume). A much better measure can be obtained by using a walk-in field cage (White et al. 1977; Calkins and Webb 1983; Chambers et al. 1983). Standard procedures for field-cage operation have been defined for fruit flies (Cayol et al. 1999, 2002; FAO/IAEA/USDA 2019); increasingly, these have been adapted for other species such as tsetse flies (Mutika et al. 2001), mosquitoes (Oliva et al. 2012; Damiens et al. 2016), and Lepidoptera (Taret et al. 2010; Mudavanhu et al. 2016).

A walk-in field cage consists of a mesh cage, at least 2.3-m high and 3-m wide, erected over a host plant or other suitable vegetation (Calkins and Webb 1983). Equal low numbers of wild males and females of the target population, as well as sterile mass-reared insects of both sexes, are introduced into the cage, and mating pairs are observed. When a genetic sexing strain is being tested, tests with only sterile males may also be conducted. The four possible outcomes (SS, SW, WS, and 
WW) are then examined for trends in the mating (Box 1). The low-density and seminatural conditions permit near-normal courtship and mating behaviour, such that any changes in the behaviour of the mass-reared insects should be apparent. The results of field-cage experiments are affected by the conditions under which the massreared insects have been reared; therefore, it is essential that conditions be tightly controlled. Each test should be replicated a minimum of 8-10 times, but data discarded when low proportions of both males and females from any strain participate in mating activities (FAO/IAEA/USDA 2019).

It is recommended that field-cage tests be performed against wild-collected insects about once per year (FAO/IAEA/USDA 2019; Lance and McInnis, this volume). Field-collected larvae must be handled properly. For example, if coffee berries infested with Mediterranean fruit flies are placed on screens and the larvae collected in pans below, the berries tend to dry out causing the larvae to exit the fruit prematurely. Then the emerged flies are smaller than normal, and this can invalidate bioassays comparing wild fly and laboratory-reared fly behaviours.

Mating competitiveness and compatibility of non-irradiated and irradiated $E$. saccharina assessed under semi-field conditions showed that wild moths did not discriminate against irradiated or laboratory-reared moths (Mudavanhu et al. 2016). Irradiated males mated significantly more times than their wild counterparts, regardless of the type of female mate, indicating that colony males were still as competitive as their wild counterparts. When male $C$. sinensis moths irradiated with 250 Gy competed with untreated wild males for untreated female mates in walk-in field cages, the Fried Competitiveness Index (Haisch 1970; Fried 1971) C value of 0.48 obtained indicated that a substerilizing dose of 250 Gy would be adequate for programmes that include an IS component (Fu et al. 2016).

Field-cage assessments are also useful for more detailed assessments of behaviour, e.g. time of mating, mating duration, remating, and the sequence and timing of specific behavioural components of courtship and pheromone calling (FAO/IAEA/USDA 2019). Standard walk-in field-cage tests were validated for use with E. postvittana. Mating frequency of E. postvittana, and the production of sex pheromone by the females, are significantly reduced with increasing radiation dose (Stringer et al. 2013). Modified test procedures were developed in which eggs are collected individually from the moths, after they had sufficient opportunity to mate in field cages, and then the females are dissected to determine the presence of one or more spermatophores (Woods et al. 2016).

In Ae. albopictus, field-cage experiments conducted in La Réunion island demonstrated that the Fried Competitiveness Index of sterile males was only 0.14 when they were released at 1-day-old, but improved to 0.53 when the release occurred after a 5-day holding period in laboratory conditions, indicating the appropriate age for release (Oliva et al. 2012). Furthermore, it was demonstrated that increasing the release ratio of sterile males led to a significant reduction in the competitiveness index, with $0.51,0.20$, and 0.18 recorded for the ratio of 100:100:100, 500:100:100, and 1000:100:100, respectively (Damiens et al. 2016). 


\begin{abstract}
Box 1. Indices of Compatibility and Competitiveness
A standard field-cage experiment results in four figures, the numbers of each of the four possible pairings formed during the test period, SS, SW, WS and WW, where S represents sterile, W wild (fertile), and males are indicated first. The categories WS and SS will be missing in the case of genetic sexing strains where sterile females are not produced. These four figures have been combined in various ways to produce indices of competitiveness and compatibility, each emphasizing a different aspect, and each with advantages and disadvantages. (For more details, see section 3.1. in FAO/IAEA/USDA (2019)).
\end{abstract}

The relative isolation index (RII) gives an indication of mating compatibility between two strains. It is calculated as:

$$
R I I=\frac{S S \times W W}{S W \times W S}
$$

A value of 1 indicates random mating, with larger values indicating assortative mating. This index is sensitive to changes in a single type of mating (e.g. a drop in the important category SW), is not affected by the overall level of participation of the different insect types, and does not depend on the ratio of sterile to wild insects in the test. The disadvantages are that the index is undefined if either SW or WS is zero, and it changes rapidly for a difference of only one if a category is small. The value of RII can be interpreted as the number of sterile males that have to be employed to be equivalent to one wild male. Values normally vary between 1.5 and 5 , and values consistently above 3 are a cause for concern.

The isolation index (ISI) is defined as:

$$
I S I=\frac{(S S+W W)-(S W+W S)}{S S+W W+S W+W S}
$$

It ranges from -1 (complete negative assortative mating) through 0 (random mating) to +1 (complete positive assortative mating). The main advantages of the ISI over the RII are that it is easier to interpret values from -1 to +1 than from 0 to infinity, it is not as sensitive to a change in a small category and is defined even when one category is zero. Values normally lie between 0.1 and 0.4 , and values over 0.5 are a cause for concern.

The ISI is normally combined with the male relative performance index (MRPI) and female relative performance index (FRPI) defined as:

$$
M R P I=\frac{(S S+S W)-(W S+W W)}{S S+S W+W S+W W} \quad F R P I=\frac{(S S+W S)-(S W+W W)}{S S+S W+W S+W W}
$$

which show the proportion of sterile males and sterile females taking part in matings, and should be used to interpret values of ISI over 0.5.

These index values can be displayed graphically (then easier to interpret), as shown below.

In contrast to the above, the Fried Competitiveness Index (Haisch 1970; Fried 1971) is based on the fertility of a particular cross combination rather than on the number participating in the cross. It is defined as:

$$
C=\frac{N}{S} \times \frac{H_{n}-H_{e}}{H_{e}-H_{s}}
$$

where $\mathrm{C}$ is competitiveness, $\mathrm{H}_{n}$ and $\mathrm{H}_{\mathrm{s}}$ are defined as the fertility of crosses between normal and irradiated males with normal females (in laboratory tests), and $\mathrm{H}_{\mathrm{e}}$ is the observed fertility in an experimental set-up with $\mathrm{N}$ normal males and $\mathrm{S}$ irradiated males. A $\mathrm{C}$ value of 1 indicates equal competitiveness; observed values usually fall between about 0.3 and 1 . It was originally devised for field tests where $\mathrm{H}_{\mathrm{e}}$ was measured by collecting egg masses in the field. The variance of $\mathrm{C}$ is given in Hooper and Horton (1981), and is a minimum when $\mathrm{H}_{\mathrm{e}}$ lies halfway between $\mathrm{H}_{\mathrm{n}}$ and $\mathrm{H}_{\mathrm{s}}$. (See also Pagendam et al. (2018) for an improved estimate of the Fried Competitiveness Index.) 


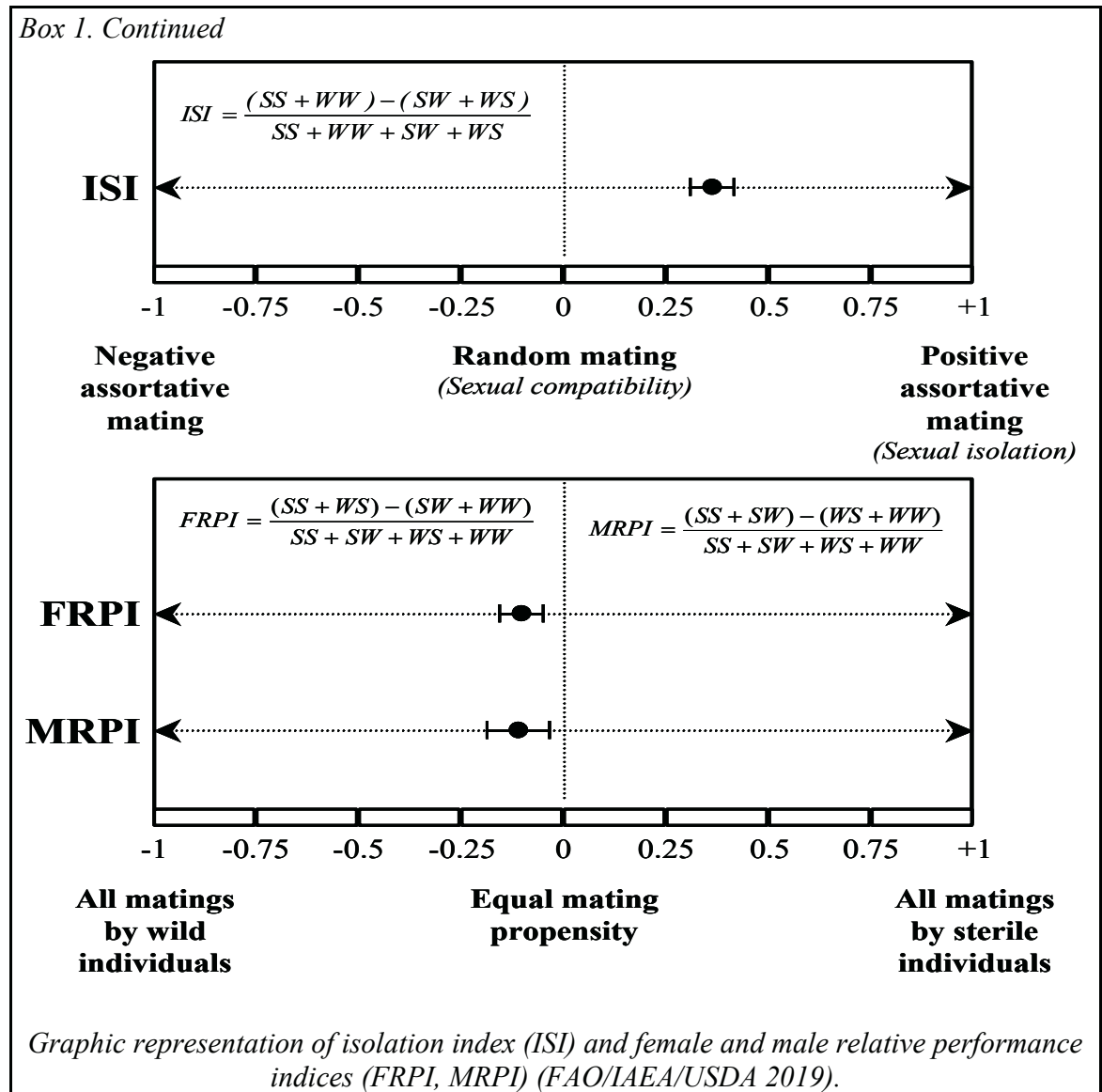

\subsection{Field Tests}

The capacity of sterile insects to survive in the field, and to disperse to feeding, mating, and resting sites, is also critical (Hendrichs et al. 1991). Survival and dispersal rates of different rearing strains can be compared using various release/recapture methods (Itô et al., this volume; Lance and McInnis, this volume; Vreysen, this volume). Such rates are often not correlated with a flight-ability test of the same lot of sterile insects in the laboratory, or even survival in field cages, because they also measure the ability of the sterile insects to find food, to respond to attractants, and to evade predators (Hendrichs et al. 1993). C. O. Calkins and T. R. Ashley (unpublished data), using mass-reared Mediterranean fruit flies irradiated at the usual dose, and at twice this dose, monitored dispersal in the field. Flies that had been exposed to twice the usual radiation dose had very low rates of dispersal and survival. Other dispersal studies by Bloem et al. (1994) compared large flies (from pupae $8-8.5 \mathrm{mg}$ in weight) with small flies (from pupae 5-5.5 $\mathrm{mg}$ ); a higher 
percentage of large than small flies was captured initially, and over a longer period of time.

Ultimately, the competitiveness of the insects should also be tested in the field, e.g. White and Mantey (1977) and Villavaso et al. (1980). It is usually not possible to detect mating pairs directly in the field, but the competitiveness of the released sterile males can be estimated by comparing the egg hatch obtained from egg masses collected in the field or from captured wild females (some with sterile, others with fertile matings) (Haisch 1970; Fried 1971; Hooper and Horton 1981; Iwahashi et al. 1983; Parker and Welch 1991). In the case of tsetse flies, the proportion of females having mated with a sterile or a wild fertile male can be estimated from dissecting and examining the reproductive status of trapped wild females (Vreysen, this volume). An open-field study, using codling moths from Canada and South Africa, indicated that moths of both origins were equally attracted to calling females from Canada and South Africa; therefore, the codling moths from Canada were compatible with codling moths established in South Africa (Bloem et al. 2010). Such an estimate takes into account all the factors that affect the induction of sterility in the wild population, including survival, dispersal, mating competitiveness, sperm transfer, remating, and sperm competition (Vreysen, this volume). The same test can also be conducted in a field cage (FAO/IAEA/USDA 2019).

In G. palpalis gambiensis, it was demonstrated that a strain colonized for more than 40 years was still competitive in the field in its country of origin (Burkina Faso) (Sow et al. 2012), and more surprisingly that it was more competitive than an autochthonous and recently colonized strain in Senegal (Bassène et al. 2017). In Glossina austeni Newstead, it was also demonstrated that sterile males were able to aggregate exactly in the same sites as the wild males, leading to a homogeneous sterile to wild ratio during the successful eradication campaign in Zanzibar (Vreysen et al. 2011).

\section{CONTROL CHARTS AND DASHBOARDS}

Data generated by quality-control assays are not very useful until they can be graphed in a sequential manner to show trends. In 1924, W. Shewhart of Bell Telephone Laboratories first developed control charts (Feigenbaum 2004). A chart consists of sequential plots of a specific quality criterion on a graph that has a central line, and upper and lower control limits (Box 2). The control limits may either be defined a priori, or more usually are derived from long-term data. For this, many samples are taken over an extended period, and the mean or median computed for the central line; the upper and lower control limits are usually three standard errors on either side of the central line (Charbonneau and Webster 1978). Each new quality-control value is plotted on the chart, and both its position and the trend over the last seven points are assessed for conformity with a set of standard rules. A single value out of bounds is less a concern than a continuing trend away from the central line. Control charts have been proposed for the Mediterranean fruit fly (Calkins et al. 1982), Lepidoptera (Fisher 1983), and tsetse flies (Timischl 1980). 
A tool is now available specifically for monitoring the key parameters in insect mass-rearing in the manner of a Dashboard (FAO/IAEA 2018). This tool links production parameters with product quality ones, and presents the data in an easily understandable graphical format to facility the management of large or small colonies by both management and technical staff.

\section{IMPACT OF LOW-QUALITY INSECTS ON ERADICATION PROGRAMMES USING THE SIT}

Calkins and Ashley (1989) attempted to put an actual monetary value on the impact of producing low-quality insects. Using Knipling's (1979) model, Calkins et al. (1996) inserted varying values of the quality of Mediterranean fruit flies established during a pilot test for quality control. Using the New World screwworm as an example, with a growth rate of 5 and an overflooding ratio of 9:1, it would take five generations to achieve eradication. Since the Mediterranean fruit fly has a much greater biotic potential, and based on its life-history parameters, a growth rate of 12 was established; an overflooding ratio of 9:1 resulted in an increase in the population each generation. The "rule of thumb" for Mediterranean fruit flies, selected during the numerous fly invasions into California, USA, is a ratio of 100:1. If all flies were $100 \%$ effective, theoretically this ratio achieves eradication in three generations.

\section{Box 2. Shewhart Control Charts}

Control charts are a well-established tool for stabilizing industrial processes. They are formed by plotting sequentially the successive values of a control parameter. These are then compared with a central line (CL), upper control limit (UCL), and lower control limit (LCL), using certain criteria to determine if the process is in control.

The graphed parameter will usually be the mean of a sample taken from the process. In industrial processes, this may be compared with a priori limits, e.g. the design diameter of a shaft and the specified tolerance limits. In insect rearing, we do not usually have such a priori limits, and base the assessment of the graphed value by comparing it with long-term historical values. The long-term mean is taken as the central line, and the upper and lower control limits are defined as three standard errors above and below the mean. By standard statistical theory, if the parameter plotted is normally distributed, random fluctuation will cause about $0.1 \%$ of the values to lie above the UCL or below the LCL. If more than one value lies outside the control limits, this indicates a systematic influence, and the process is said to be out of statistical control.

Two examples of control charts are given below - monitoring the fecundity of the G. pallidipes colony at the FAO/IAEA Seibersdorf laboratories. The parameter plotted is weekly fecundity, expressed as pupae per live female per ovarian cycle (10 days) $(\mathrm{P} / \mathrm{F} / 10 \mathrm{~d})$. The central line is the average value over a 105-week period (2003-2004). Since only a single measurement is taken each week, variability is estimated by using the difference between successive pairs of values, yielding a moving range, from which the standard deviation is derived.

The first chart shows the individual values plotted for 2004, and the UCL, CL, and LCL. Since increased fertility is not a problem, only the LCL is considered further. Another line has been added, the lower warning line (LWL), at two standard errors below the CL; this draws attention to values approaching the limit.

The second chart uses an exponential weighted moving average (includes all historical data points but weights the most recent more highly). This is less sensitive to individual extreme values, but more clearly shows longer-term trends. In this case, the control limits are not straight lines, but are asymptotic to the control limits in the previous example. Both charts show that, in 2004, fecundity was usually better than average, but fell towards the end of the year. 
Box 2. Continued

Individuals Chart

Fecundity of Glossina pallidipes colony at Seibersdorf, 2004

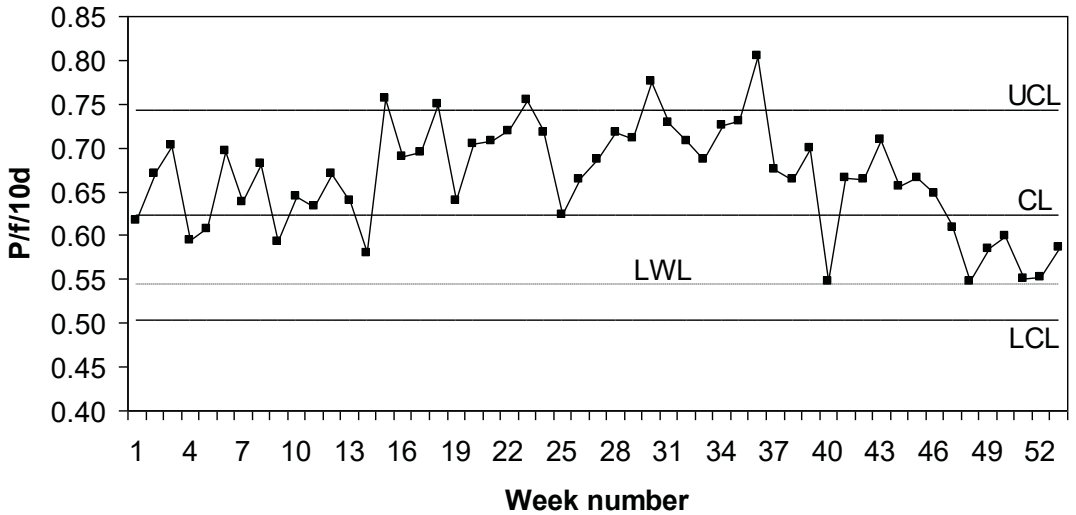

Exponentially Weighted Moving Average Chart

Fecundity of Glossina pallidipes colony at Seibersdorf, 2004

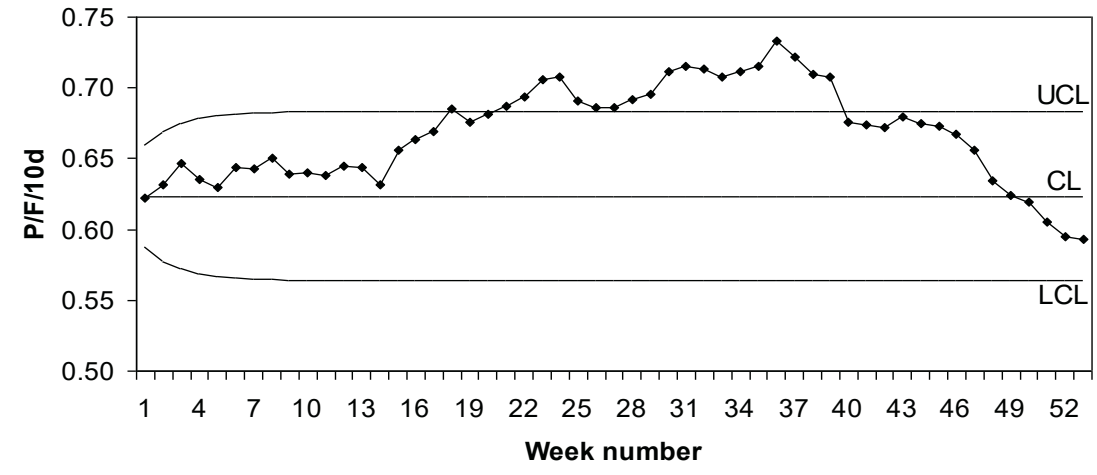

However, when the fly quality equals the minimum acceptable level of quality, the effective release ratio becomes 23:1, and it takes five generations to achieve eradication (Calkins and Ashley 1989).

When the actual level of fly quality was inserted into the model, giving an effective ratio of $54: 1$, only four generations were needed for eradication. However, if the flies were only half as effective, the cost per hectare (to produce and utilize sterile flies that are of only moderate quality) becomes almost twice as much. Furthermore, increasing the frequency of releases or the number of released sterile insects can only compensate for low quality up to a point - beyond which increased 
numbers cannot make up for such deficiencies (Itô et al., this volume). Therefore, it is economically beneficial to rear high-quality rather than low-quality insects (Calkins and Ashley 1989).

A population model developed for E. postvittana indicated that releasing 300 Gy-irradiated moths would result in a $95 \%$ probability of extinction (if the ratio of released to wild moths exceeded 6.4:1). The model indicated an optimal release interval of $1 \mathrm{wk}$, but higher overflooding ratios would achieve eradication more rapidly. The model also predicted little advantage to releasing only male moths as compared with both sexes. Using a dose of $200 \mathrm{~Gy}$, as part of an inherited sterility programme, would reduce (due to the resulting $\mathrm{F}_{1}$ sterility) by $1 / 3$ the required number of factory moths as compared with releasing lower quality moths irradiated with 300 Gy (Kean et al. 2011; Rull et al. 2012).

For the year 2001, a cost of USD 216 per million sterile male Mediterranean fruit flies was calculated when mass-reared at the El Pino facility, Guatemala (using a $t s l$ genetic sexing strain) (see Table 1 in Hendrichs et al. 2002; Enkerlin 2003). At these large-scale production levels, these are probably the cheapest sterile insects in the world, although the cost increases significantly at lower production levels. The cost per million tsl males is more or less equivalent to the cost per million males of the usual bisexual strain. However, the big difference (in terms of cost savings) is in the transport and release operations, where sterile $t s l$ males cost half as much as males of the bisexual strain (Caceres et al. 2004). In addition, male-only releases introduce three or four times more sterility into the target population than do bisexual releases (Robinson et al. 1999; Rendón et al. 2000, 2004).

There were several technical and managerial reasons why the ill-fated New World screwworm eradication project on the island of Jamaica was not successful (Vreysen et al. 2007; Dyck, Reyes Flores et al., this volume). However, the reduction in the quality of the sterile pupae received from the screwworm massrearing facility in Mexico (as evidenced by a gradual reduction in the average weight of the pupae) was certainly one of the critical technical issues that contributed to the failure of the programme (see Fig. 3 in Vreysen et al. 2007).

\section{CHANGES IN INSECT BEHAVIOUR CAUSED BY LABORATORY REARING}

Selection during colonization and mass-rearing usually changes the biology and behaviour of the reared insects (Iwahashi et al. 1983; Calkins 1989; Miyatake 1993, 1998a, b, 2002; Miyatake and Haraguchi 1996; Miyatake and Yamagishi 1999; Cayol 2000; Shimoji and Miyatake 2002; Maor et al. 2004; Caprio 2009; Meza et al. 2014; Aceituno-Medina et al. 2017). The oviposition medium is often completely different from that in natural conditions, e.g. fabric, paper, a membrane, a plastic bottle with small holes. Adult-emergence cages serve as both mating and oviposition cages, and males often harass ovipositing females. In these colony-holding cages, insects are maintained at abnormally high densities, and there is no space to develop mating aggregations or swarms, or to attract females through producing a pheromone. All insects are of the same age, and frequently more females are placed in a production cage than males, reducing the need for courtship or competition 
between males. Many matings consist of brief courtships or, in some cases, even forced matings. Adult insects are discarded as soon as egg production begins to wane, thereby selecting for early maturing insects. In this situation, it is advantageous for females to mate quickly and maximize the number of progeny. It is disadvantageous for males to retain elaborate courtships, or for females to discriminate in mate selection. If abbreviated courtship becomes fixed in the population, this courtship repertoire may not be acceptable to wild females (Briceño and Eberhard 1998).

The mating competitiveness of laboratory-reared and wild Mediterranean fruit flies was examined in natural mating arenas (leks) (Zapien et al. 1983; Shelly 1995). Although the laboratory-reared males readily joined leks, and displayed calling behaviour similar to that of wild flies, relatively few laboratory-reared males were able to mate with wild females. The sterile males either failed to attract wild females to their positions in the lek, or the courtship repertoire was not acceptable to attracted wild females. In addition, on cloudy days, sterile males refrained from participating in sexual activities, and thus could not compete for wild females during such low-light-intensity conditions (Zapien et al. 1983).

In a mass-rearing environment (unlike the field), light, temperature, and relative humidity are often constant. Exposure to constant and optimal conditions of light, temperature, and relative humidity can select for individuals that are better adapted to these conditions, but lack the ability to adjust to fluctuating environments (Cayol 2000). If insects are reared for generations in constant light, changes in the temporal mating periods may result. In field-cage tests in Florida, laboratory-reared Caribbean fruit flies mated in the afternoon and completed mating activities long before wild flies began to mate near dusk (C. O. Calkins, unpublished data).

\section{REMEDIAL ACTIONS TO RESTORE EFFECTIVENESS OF REARED INSECTS}

When a colony of insects, used for the SIT, begins to deteriorate in effectiveness, there are several ways to restore it, including a change in colony management procedures. However, if genetic selection is involved, the problem may be more difficult to solve, and the establishment of a new colony from the target population may be required. Changed management procedures may reverse the selection, or at least slow down colony deterioration (Fisher and Caceres 2000; Liedo et al. 2007; Parker, Mamai et al., this volume).

If the causes are identified, specific problems detected by various tests can be addressed to reverse selection (Cáceres et al. 2007), e.g. adult cages, designed to increase the internal surfaces, significantly improved the mating competitiveness of mass-reared males (Liedo et al. 2007). Alternatively, adult cages designed to require insects to fly before having the opportunity to eat and drink automatically selects against non-flyers. In the cases of the New World screwworm (Wyss 2002) and codling moth (Dyck et al. 1993), adult insects must be able to fly to be collected in a cold room; they are then taken to the field for release.

Another problem that often develops in a reared colony is flies lacking irritability (section 4.10.). As a result, released sterile insects become easy prey to many of the 
predators that they encounter in the field. If an automatic technique to select against such adults in the adult cage could be developed, this problem would be reduced.

Mating compatibility appears to involve heritable traits that, to a certain extent, can be manipulated. Changes in temporal mating periods may be corrected, at least partially, by implementing egg collection and other regimes for the colony production that maintain the normal distribution of relevant characters of the colonized population (Miyatake 1995), and holding adult colony flies under natural light/dark cycles. Also, fluctuating temperatures in the adult colony room would increase the tolerance for changing field conditions.

The mating performance of sterile fruit flies may decrease under extreme or marginal habitats, such as high altitudes where cooler temperatures prevail. While developing a RAPID quality-control system for early warning of poor fly performance, Boller et al. (1981) reared Mediterranean fruit flies in a laboratory at cool temperatures to determine if they would still mate and perform other tasks. They found that there was enough genetic variability in a colony, normally reared at optimal constant temperature, to perform at cool temperatures after being reared at these temperatures for only a few generations.

Haynes and Smith (1989) discovered that, when sterile boll weevils were fed on squares (cotton blossom buds) instead of plugs of artificial diet before release, locomotor activity increased, mortality decreased, and mating attractiveness increased by $16 \%$ when compared with that of control weevils fed on diet plugs.

There are several possible reasons why a reared insect becomes incompatible with a wild one, such as genetic changes caused by the rearing process, genetic drift, or a change in a wild population that has been exposed to released sterile insects for "too many" generations. Hibino and Iwahashi (1991) reported that wild female melon flies of an island population, exposed to sterile males late in an AW-IPM programme that integrated the SIT, became unreceptive to sterile males (Lance and McInnis, this volume; Whitten and Mahon, this volume). Such changes may appear as temporal changes in the mating period, subtle changes in the courtship behaviour or in the chemical make-up of a pheromone, changes in acoustical signals, etc. (Sivinski et al. 1989; Briceño and Eberhard 1998). In these cases, there may be no alternative except to replace the mass-reared colony with a new strain from the target population.

However, in situations where the rearing process itself is responsible for the change, changing the strain without correcting the process will not solve the problem. As described above, the changes that occur while domesticating an insect population are major ones, and do not happen in one or two generations. One solution is to continually develop new strains, just in case the current one deteriorates. In any case, this may be necessary to prevent possible incompatibilities as the SIT activities expand into new geographic areas that have potentially different target populations. However, strain replacement is extremely expensive (Mangan 1992), and a successful strain should not be discarded unless it is found to be inadequate. It is costly to expand a colony, conduct quality-control tests, determine rearing characteristics, and evaluate field performance. Nevertheless, regular strain replacement in the New World screwworm colony in Mexico became a standard procedure (Hofmann 1985; Parker, Mamai et al., this volume). 
A less drastic cure is to incorporate wild genes into the colony genome. Wild corn earworm Helicoverpa zea (Boddie) moths from St. Croix, US Virgin Islands, were incorporated into a colony in Tifton, GA, USA; as a result, released moths mated much more frequently with wild moths (Young et al. 1975). However, this approach is not always successful. The wild individuals being introduced must compete in the artificial conditions to which moths in the domestic colony have already adapted. In the case of fruit flies, one solution is to replace only the males in the colony with wild males. For wild females, the most problematic aspect of adaptation is the oviposition device (Ahmad et al. 2014); by excluding wild females from the new introduction, this part of the selection process is avoided.

In the case of tsetse flies, trying to incorporate wild genes from the wild target population of G. palpalis gambiensis from Senegal into an old domestic colony from Burkina Faso (through back-crossing on males) failed. Even though it was maintained for many generations, the cross-bred line did not develop a satisfactory fecundity, whereas the new colonized strain rapidly improved during the same time to reach the same fecundity as the domestic one (Pagabeleguem et al. 2016).

Sometimes an improvement in the general vigour of a colony can be achieved by reducing the stress of the mass-rearing regime of the mother colony (Orozco-Dávila et al. 2014). Boller and Calkins (1984) used a relaxed low-density rearing method for a strain of Mediterranean fruit flies, and within two generations the vigour and size of the males increased. A system for limiting stress on a mother colony, called filter rearing (Fisher and Caceres 2000), also prevents the accumulation of deleterious traits from the high-density rearing stages back to the mother colony (Parker, Mamai et al., this volume). In this system, the mother colony is held under low-density low-stress conditions. Surplus insects from this colony are continuously fed into a sequence of high-density amplification steps to the final release colony, but the mother colony is kept separate and never receives material back from the high-density steps. The use of such a filter system has several advantages. Since the mother colony is small, it is possible to keep the insects under low-density conditions, and apply sexual competition or directed selection to them to restore or maintain desirable traits (Tejeda et al. 2017; Quintero-Fong et al. 2018). If necessary, by establishing a new mother colony, the whole production can be easily switched to a new strain.

If a colony is replaced because the rearing process is responsible for developing an inferior strain of insects, and the particular feature of the rearing method responsible for the change in insect behaviour is not adjusted, the new colony will rapidly develop the same inferior behaviour. This domestication takes place in just a few generations during the "bottleneck" that occurs in the initial phase of colonization (Zygouridis et al. 2014). Leppla et al. (1980) reported the complete adaptation of a noctuid moth to a laboratory environment in five to seven generations. The adaptation of the Caribbean fruit fly to a rearing regime, where performances in the laboratory bioassays were the same as those for the reared colony, took three or four generations (C. O. Calkins, unpublished data). Pashley and Proverbs (1981) noted a gradual change over time in the allozymes of reared codling moths, and predicted that this change could affect mating interactions with a wild population. 


\section{QUALITY-CONTROL MANUALS}

The first system of quality control was developed in 1978 by E. Boller for the Mediterranean fruit fly (Boller et al. 1981). It consisted of behavioural tests that included a pupal calibration sorting process to determine the array of pupal sizes, a startle test to measure irritability, an olfactometer to determine the age and time of day when males began to produce pheromone and females began to respond, a mating propensity test, a new ratio test, and an isolation index.

An operational quality-control manual for Mediterranean fruit flies, used at the Moscamed factories in Mexico and Guatemala and in other fruit fly programmes in Latin America, was developed by Orozco-Dávila et al. (1983), and subsequently modified or updated by Brazzel et al. (1986), Ashley (1987), and Calkins et al. (1996). To harmonize tests in these manuals, standardize quality-control tests, and allow comparisons for commercial and transboundary shipments of sterile insects, an international quality-control manual was produced in 2003 and updated in 2019 (FAO/IAEA/USDA 2019); it is being used in most fruit fly programmes.

Specific quality-control manuals have been produced for some other insects, including the New World screwworm (Lopez et al. 1995), tsetse flies (Feldmann 1994; Gooding et al. 1997; IAEA 2012), and Lepidoptera (Fisher 1983). This latter one included process-control charts that were sensitive tools for identifying changes in insects during colonization, and a feedback loop back to the production. Manuals for mass-rearing specific insects often include sections on quality control, including those for some other fruit fly species (Spencer and Fujita 1997), codling moth (Dyck 2010), tsetse flies (FAO/IAEA 2006), and Anopheles mosquitoes (FAO/IAEA 2017b).

\section{REFERENCES}

Abd-Alla, A. M. M., H. M. Kariithi, A. H. Mohamed, E. Lapiz, A. G. Parker, and M. J. B. Vreysen. 2013. Managing hytrosavirus infections in Glossina pallidipes colonies: feeding regime affects the prevalence of salivary gland hypertrophy syndrome. PLOS ONE 8(5): e61875. https://doi.org/10.1371/journal.pone.0061875

Aceituno-Medina, M., J. P. Rivera-Ciprian, and E. Hernández. 2017. Influence of pupation substrate on mass production and fitness of adult Anastrepha obliqua Macquart (Diptera: Tephritidae) for sterile insect technique application. Journal of Economic Entomology 110: 2397-2405. https://doi.org/10.1093/jee/tox279

Agee, H. R., and M. L. Park. 1975. Use of the electroretinogram to measure the quality of vision of the fruit fly. Environmental Letters 10(2): 171-176. https://doi.org/10.1080/00139307509435818

Ahmad, S., V. Wornoayporn, P. Rempoulakis, E. A. Fontenot, I. U. Haq, C. Caceres, H. F. Paulus, and M. J. B. Vreysen. 2014. Hybridization and use of grapes as an oviposition substrate improves the adaptation of olive fly Bactrocera oleae (Rossi) (Diptera: Tephritidae) to artificial rearing conditions. International Journal of Industrial Entomology 29: 198-206.

Ahmad, S., I. ul Haq, C. Cáceres, U. Sto Tomas, T. Dammalage, K. Gembinsky, H. Paulus, M. J. B. Vreysen, and P. Rempoulakis. 2018. One for all: mating compatibility among various populations of olive fruit fly (Diptera: Tephritidae) for application of the sterile insect technique. PLOS ONE 13(11): e0206739. https://doi.org/10.1371/journal.pone.0206739

Alemu, T., B. Kapitano, S. Mekonnen, G. Aboset, M. Kiflom, B. Bancha, G. Woldeyes, K. Bekele, and U. Feldmann. 2007. Area-wide control of tsetse and trypanosomosis: Ethiopian experience in the Southern Rift Valley, pp. 325-335. In M. J. B. Vreysen, A. S. Robinson and J. Hendrichs (eds.), Area-wide control of insect pests: from research to field implementation. Springer, Dordrecht, The Netherlands. https:/www.iaea.org/sites/default/files/area-wide-control-insect-pests-book.pdf 
Ashley, T. R. 1987. An analytical system for quality control data. Mediterranean fruit fly pilot test program - Guatemala, 1984-1987. US Department of Agriculture, Agricultural Research Service.

Ashraf, M., N. Chatha, K. Ohinata, and E. J. Harris. 1975. Melon flies: dosage-response and sexual competitiveness after treatment with gamma irradiation in a nitrogen atmosphere. Journal of Economic Entomology 68: 838-840. https://doi.org/10.1093/jee/68.6.838

Balestrino, F., A. Puggioli, M. Carrieri, J. Bouyer, and R. Bellini. 2017. Quality control methods for Aedes albopictus sterile male production. PLOS Neglected Tropical Diseases 11(9): e0005881. https://doi.org/10.1371/journal.pntd.0005881

Barnes, B. N., J. H. Hofmeyr, S. Groenewald, D. E. Conlong, and M. Wohlfarter. 2015. The sterile insect technique in agricultural crops in South Africa: a metamorphosis ... but will it fly? African Entomology 23: 1-18. https://doi.org/10.4001/003.023.0103

Bartlett, A. C. 1984. Genetic changes during insect domestication, pp. 2-8. In E. G. King and N. C. Leppla (eds.), Advances and challenges in insect rearing. USDA, ARS, New Orleans, LA, USA.

Bassène, M. D., M. T. Seck, S. Pagabeleguem, A. G. Fall, B. Sall, M. J. B. Vreysen, G. Gimonneau, and J. Bouyer. 2017. Competitiveness and survival of two strains of Glossina palpalis gambiensis in an urban area of Senegal. PLOS Neglected Tropical Diseases 11(12): e0006172. https://doi.org/10.1371/journal.pntd.0006172

Bernon, G. L., and N. C. Leppla. 1994. Nutrition and quality control in mass rearing of phytophagous insects, pp. 211-220. In J. P. R. Ochieng'-Odero (ed.), Techniques of insect rearing for the development of integrated pest and vector management strategies. ICIPE Science Press, Nairobi.

Bigler, F. 1994. Quality control in insect rearing systems, pp. 189-209. In J. P. R. Ochieng'-Odero (ed.), Techniques of insect rearing for the development of integrated pest and vector management strategies. ICIPE Science Press, Nairobi, Kenya.

Bloem, K., S. Bloem, D. Chambers, and E. Muniz. 1993a. Field evaluation of quality: releaserecapture of sterile medflies of different sizes, pp. 295-296. In M. Aluja and P. Liedo (eds.), Fruit flies. Biology and management. Springer-Verlag, New York, NY, USA.

Bloem, K., S. Bloem, N. Rizzo, and D. Chambers. 1993b. Female medfly refractory period: effect of male reproductive status, pp. 189-190. In M. Aluja and P. Liedo (eds.), Fruit flies. Biology and management. Springer-Verlag, New York, NY, USA.

Bloem, K. A., S. Bloem, and D. L. Chambers. 1994. Field assessment of quality: release-recapture of mass-reared Mediterranean fruit flies (Diptera: Tephritidae) of different sizes. Environmental Entomology 23: 629-633. https://doi.org/10.1093/ee/23.3.629

Bloem, S., K. A. Bloem, N. Rizzo, and D. L. Chambers. 1993c. Female medfly refractory period: effect of first mating with sterile males of different sizes, pp. 191-192. In M. Aluja and P. Liedo (eds.), Fruit flies. Biology and management. Springer-Verlag, New York, NY, USA.

Bloem, S., K. A. Bloem, J. E. Carpenter, and C. O. Calkins. 1999a. Inherited sterility in codling moth (Lepidoptera: Tortricidae): effect of substerilizing doses of radiation on insect fecundity, fertility, and control. Annals of the Entomological Society of America 92: 222-229. https://doi.org/10.1093/aesa/92.2.222

Bloem, S., K. A. Bloem, J. E. Carpenter, and C. O. Calkins. 1999b. Inherited sterility in codling moth (Lepidoptera: Tortricidae): effect of substerilizing doses of radiation on field competitiveness. Environmental Entomology 28: 669-674. https://doi.org/10.1093/ee/28.4.669

Bloem, S., K. A. Bloem, J. E. Carpenter, and C. O. Calkins. 2001. Season-long releases of partially sterile males for control of codling moth (Lepidoptera: Tortricidae) in Washington apples. Environmental Entomology 30: 763-769. https://doi.org/10.1603/0046-225X-30.4.763

Bloem, S., J. E. Carpenter, T. L. Blomefield, and C. Harrison. 2010. Compatibility of codling moths Cydia pomonella (Linnaeus) (Lepidoptera: Tortricidae) from South Africa with codling moths shipped from Canada. Journal of Applied Entomology 134: 201-206. https://doi.org/10.1111/j.1439-0418.2009.01416.x

Blomefield, T. L., S. Bloem, and J. E. Carpenter. 2010. Effect of radiation on fecundity and fertility of codling moth Cydia pomonella (Linnaeus) (Lepidoptera: Tortricidae) from South Africa. Journal of Applied Entomology 134: 216-220. https://doi.org/10.1111/j.1439-0418.2008.01377.x

Boersma, N., and J. E. Carpenter. 2016. Influence of holding temperature and irradiation on field performance of mass-reared Thaumatotibia leucotreta (Lepidoptera: Tortricidae). Florida Entomologist 99(Special Issue 1): 215-221. https://journals.flvc.org/flaent/article/view/88504

Boller, E. F. 1972. Behavioral aspects of mass-rearing of insects. Entomophaga 17: 9-25.

Boller, E. F. 2002. History of quality control in mass-reared insects, pp. 1-5. In N. C. Leppla, K. A. Bloem and R. F. Luck (eds.), Quality Control for Mass-Reared Arthropods. Proceedings of the eighth 
and ninth workshops of the International Organization for Biological Control Working Group on Quality Control for Mass Reared Arthropods.

http://www.mrqa.unibo.it/proceedings/Proceedings\%20Cali\%20Santa\%20Barbara.pdf

Boller, E. F., and C. O. Calkins. 1984. Measuring, monitoring and improving the quality of massreared Mediterranean fruit flies, Ceratitis capitata (Wied.): 3 . Improvement of quality by selection. Journal of Applied Entomology 98: 1-15. https://doi.org/10.1111/j.1439-0418.1984.tb02678.x

Boller, E. F., and D. L. Chambers. 1977. Quality control: an idea book for fruit fly workers. International Organization for Biological Control of Noxious Animals and Plants, West Palaearctic Regional Section. 162 pp.

Boller, E. F., B. I. Katsoyannos, U. Remund, and D. L. Chambers. 1981. Measuring, monitoring and improving the quality of massreared Mediterranean fruit flies, Ceratitis capitata Wied. 1. The RAPID quality control system for early warning. Journal of Applied Entomology 92: 67-83. https://doi.org/10.1111/j.1439-0418.1981.tb01653.x

Bonizzoni, M., L. M. Gomulski, S. Bertin, F. Scolari, C. R. Guglielmino, B. Yuval, G. Gasperi, and A. R. Malacrida. 2007. Unfaithful Mediterranean fruit fly Ceratitis capitata females: impact on the SIT?, pp. 175-182. In M. J. B. Vreysen, A. S. Robinson and J. Hendrichs (eds.), Area-wide control of insect pests. From research to field implementation. Springer, Dordrecht, The Netherlands. https://www.iaea.org/sites/default/files/area-wide-control-insect-pests-book.pdf

Bouyer, J., M. T. Seck, B. Sall, E. Y. Ndiaye, L. Guerrini, and M. J. B. Vreysen. 2010. Stratified entomological sampling in preparation for an area-wide integrated pest management program: the example of Glossina palpalis gambiensis (Diptera: Glossinidae) in the Niayes of Senegal. Journal of Medical Entomology 47: 543-552. https://doi.org/10.1093/jmedent/47.4.543

Brazzel, J. R., C. Calkins, D. L. Chambers, and D. B. Gates. 1986. Required quality control tests, quality specifications, and shipping procedures for laboratory produced Mediterranean fruit flies for sterile insect control programs. USDA/APHIS Plant Protection and Quarantine Report 81: 51.

Briceño, R. D., and W. G. Eberhard. 1998. Medfly courtship duration: a sexually selected reaction norm changed by crowding. Ethology, Ecology and Evolution 10: 369-382. https://doi.org/10.1080/08927014.1998.9522850

Brown, R. L., M. Stanbury, A. M. El-Sayed, J. Laban, R. Butler, and D. M. Suckling. 2016. Locomotion activity meter for quality assessment of mass-reared sterile male moths (Lepidoptera). Florida Entomologist 99(Special Issue 1): 131-137. http://journals.fcla.edu/flaent/article/view/88494

Buckner, E. A., B. W. Alto, and L. P. Lounibos. 2013. Vertical transmission of Key West dengue-1 virus by Aedes aegypti and Aedes albopictus (Diptera: Culicidae) mosquitoes from Florida. Journal of Medical Entomology 50: 1291-1297. https://doi.org/10.1603/ME13047

Burk, T. 1982. Evolutionary significance of predation on sexually signaling males. Florida Entomologist 65: 90-104. http://journals.fcla.edu/flaent/article/view/57655/55334

Burk, T., and J. C. Webb. 1983. Effect of male size on calling propensity, song parameters, and mating success in Caribbean fruit flies, Anastrepha suspensa (Loew) (Diptera: Tephritidae). Annals of the Entomological Society of America 76: 678-682. https://doi.org/10.1093/aesa/76.4.678

Bush, G. L., R. W. Neck, and G. B. Kitto. 1976. Screwworm eradication: inadvertent selection for noncompetitive ecotypes during mass rearing. Science 193(4252): 491-493. https://science.sciencemag.org/content/193/4252/491 DOI: 10.1126/science.941019

Caceres, C., J. P. Cayol, W. Enkerlin, G. Franz, J. Hendrichs, and A. S. Robinson. 2004. Comparison of Mediterranean fruit fly (Ceratitis capitata) (Tephritidae) bisexual and genetic sexing strains: development, evaluation and economics, pp. 367-381. In B. N. Barnes (ed.), Proceedings of the 6th International Symposium on Fruit Flies of Economic Importance, 6-10 May 2002, Stellenbosch, South Africa. Isteg Scientific Publications, Irene, South Africa. https://nucleus.iaea.org/sites/naipc/twd/Documents/6thISFFEI_Proceedings/6th-ISFFEI-Proceedings2004-Stellenbosch-South-Africa.pdf

Cáceres, C., D. McInnis, T. Shelly, E. Jang, A. Robinson, and J. Hendrichs. 2007. Quality management systems for fruit fly (Diptera: Tephritidae) sterile insect technique. Florida Entomologist 90: 1-9. http://journals.fcla.edu/flaent/article/view/75606/73264

Cáceres, C., D. F. Segura, M. T. Vera, V. Wornoayporn, J. L. Cladera, P. Teal, P. Sapountzis, K. Bourtzis, A. Zacharopoulou, and A. S. Robinson. 2009. Incipient speciation revealed in Anastrepha fraterculus (Diptera: Tephritidae) by studies on mating compatibility, sex pheromones, hybridization, and cytology. Biological Journal of the Linnean Society 97: 152-165. https://doi.org/10.1111/j.1095-8312.2008.01193.x 
Cagnotti, C. L., M. M. Viscarret, M. B. Riquelme, E. N. Botto, L. Z. Carabajal, D. F. Segura, and S. N. López. 2012. Effects of X-rays on Tuta absoluta for use in inherited sterility programmes. Journal of Pest Science 85: 413-421. https://link.springer.com/article/10.1007/s10340-012-0455-9

Cagnotti, C. L., A. V. Andorno, C. M. Hernández, L. C. Paladino, E. N. Botto, and S. N. López. 2016. Inherited sterility in Tuta absoluta (Lepidoptera: Gelechiidae): pest population suppression and potential for combined use with a generalist predator. Florida Entomologist 99(Special Issue 1): 87-94. http://journals.fcla.edu/flaent/article/view/88490

Calkins, C. 1989. Lekking behaviour in fruit flies and its implications for quality assessments, pp. 135139. In R. Cavalloro (ed.), Proceedings, Symposium: Fruit Flies of Economic Importance, 7-10 April 1987, Rome, Italy. A. A. Balkema, Rotterdam, The Netherlands.

Calkins, C. O., and T. R. Ashley. 1989. The impact of poor quality of mass-reared Mediterranean fruit flies on the sterile insect technique used for eradication. Journal of Applied Entomology 108: 401408. https://doi.org/10.1111/j.1439-0418.1989.tb00474.x

Calkins, C. O., and J. C. Webb. 1983. A cage and support framework for behavioral tests of fruit flies in the field. Scientific Notes. Florida Entomologist 66(4): 512-514. http://journals.fcla.edu/flaent/article/view/57858/55537

Calkins, C. O., D. L. Chambers, and E. F. Boller. 1982. Quality control of fruit flies in a sterile insect release programme, pp. 341-355. In Sterile insect technique and radiation in insect control. Proceedings of a Symposium, Neuherberg, Germany, 29 June-3 July 1981. STI/PUB/595, IAEA, Vienna, Austria. https://www.iaea.org/sites/default/files/sit-radiation-proceedings-1982.pdf

Calkins, C. O., R. Nguyen, K. Corwin, and J. R. Brazzel. 1988. Evaluations of quality of irradiated Mediterranean fruit fly, Ceratitis capitata (Wiedemann) (Diptera: Tephritidae), at the release site in Miami, Florida during an eradication program in 1985. Florida Entomologist 71(3): 346-351. http://journals.fcla.edu/flaent/article/view/58401/56080

Calkins, C. O., T. R. Ashley, and D. L. Chambers. 1996. Implementation of technical and managerial systems for quality control in Mediterranean fruit fly (Ceratitis capitata) sterile release programs, pp. 399-404. In B. A. McPheron and G. J. Steck (eds.), Fruit fly pests: a world assessment of their biology and management. St. Lucie Press, Delray Beach, FL, USA.

Callahan, A. G., P. A. Ross, and A. A. Hoffmann. 2018. Small females prefer small males: size assortative mating in Aedes aegypti mosquitoes. Parasites and Vectors 11: 445. https://doi.org/10.1186/s13071-018-3028-9

Caprio, M. A. 2009. Genetic considerations and strategies for rearing high quality insects, pp. 87-95. In J. C. Schneider (ed.), Principles and procedures for rearing high quality insects. Mississippi State University, Mississippi State, MS, USA.

Carlson, J., E. Suchman, and L. Buchatsky. 2006. Densoviruses for control and genetic manipulation of mosquitoes. Advances in Virus Research 68: 361-392. https://doi.org/10.1016/S0065-3527(06)68010-X

Carpenter, J. E., S. Bloem, and S. Taggart. 2010. Effect of rearing strategy and gamma radiation on fecundity and fertility of codling moth Cydia pomonella (Linnaeus) (Lepidoptera: Tortricidae). Journal of Applied Entomology 134(3): 221-226. https://doi.org/10.1111/j.1439-0418.2009.01388.x

Carpenter, J. E., T. Blomefield, and M. J. B. Vreysen. 2012. A flight cylinder bioassay as a simple, effective quality control test for Cydia pomonella. Journal of Applied Entomology 136(9): 711-720. https://doi.org/10.1111/j.1439-0418.2012.01711.x

Cayol, J. P. 2000. Changes in sexual behavior and life history traits of tephritid species caused by massrearing processes, pp. 843-860. In M. Aluja and A. L. Norrbom (eds.), Fruit flies (Tephritidae): phylogeny and evolution of behaviour. CRC Press, Boca Raton, FL, USA.

Cayol, J. P., J. Vilardi, E. Rial, and M. T. Vera. 1999. New indices and method to measure the sexual compatibility and mating performance of Ceratitis capitata (Diptera: Tephritidae) laboratory-reared strains under field cage conditions. J. Econ. Ent. 92: 140-145. https://doi.org/10.1093/jee/92.1.140

Cayol, J. P., P. Coronado, and M. Taher. 2002. Sexual compatibility in medfly (Diptera: Tephritidae) from different origins. Fl. Ent. 85: 51-57. http://journals.fcla.edu/flaent/article/view/75044/72702

Chakroun, S., P. Rempoulakis, K. Lebdi-Grissa, and M. J. B. Vreysen. 2017. Gamma irradiation of the carob or date moth Ectomyelois ceratoniae: dose-response effects on egg hatch, fecundity, and survival. Ent. Exper. et Appl. 164(3, Special Issue): 257-268. https://doi.org/10.1111/eea.12617

Chambers, D. L., C. O. Calkins, E. F. Boller, Y. Itô, and R. T. Cunningham. 1983. Measuring, monitoring and improving the quality of mass-reared Mediterranean fruit flies, Ceratitis capitata (Wied.). 2. Field tests confirming and extending laboratory results. Journal of Applied Entomology 95(1-5): 285-303. https://doi.org/10.1111/j.1439-0418.1983.tb02646.x 
Charbonneau, H. C., and G. L. Webster. 1978. Industrial quality control. Prentice Hall, Englewood Cliffs, NJ, USA. 391 pp.

Chidawanyika, F., and J. S. Terblanche. 2011. Rapid thermal responses and thermal tolerance in adult codling moth Cydia pomonella (Lepidoptera: Tortricidae). Journal of Insect Physiology 57: 108-117. https://doi.org/10.1016/j.jinsphys.2010.09.013

Churchill-Stanland, C., R. Stanland, T. T. Y. Wong, N. Tanaka, D. O. McInnis, and R. V. Dowell. 1986. Size as a factor in the mating propensity of Mediterranean fruit flies, Ceratitis capitata (Diptera: Tephritidae), in the laboratory. Journal of Economic Entomology 79: 614-619. https://doi.org/10.1093/jee/79.3.614

Churchill-Stanland, C., R. Stanland, and T. Ashley. 1987. Mediterranean fruit fly, Ceratitis capitata, population cycle and body size ranges and fluctuations in coffee, pp. 411-412. In A. P. Economopoulos (ed.), Fruit Flies. Proceedings: Second International Symposium, 16-21 September 1986, Colymbari, Crete, Greece. Elsevier Science Publishers, Amsterdam, The Netherlands.

Culbert, N. J., R. S. Lees, M. J. B. Vreysen, A. C. Darby, and J. R. L. Gilles. 2017. Optimised conditions for handling and transport of male Anopheles arabiensis: effects of low temperature, compaction, and ventilation on male quality. Entomologia Experimentalis et Applicata 164(3, Special Issue): 276-283. https://doi.org/10.1111/eea.12610

Culbert, N. J., F. Balestrino, A. Dor, G. S. Herranz, H. Yamada, T. Wallner, and J. Bouyer. 2018. A rapid quality control test to foster the development of genetic control in mosquitoes. Scientific Reports 8: 16179. https://www.nature.com/articles/s41598-018-34469-6

Dame, D. A., D. R. Birkenmeyer, and E. Bursell. 1969. Development of the thoracic muscle and flight behaviour of Glossina morsitans orientalis Vanderplank. Bulletin of Entomological Research 59(2): 345-350. https://doi.org/10.1017/S000748530000328X

Damiens, D., P. O. Tjeck, C. Lebon, G. Le Goff, and L. C. Gouagna. 2016. The effects of age at first mating and release ratios on the mating competitiveness of gamma-sterilised Aedes albopictus males under semi field conditions. Vector Biology Journal 1(1): 1-6. DOI: 10.4172/2473-4810.1000107 https://www.scitechnol.com/peer-review/the-effects-of-age-at-first-mating-and-release-ratios-on-themating-competitiveness-of-gamma-sterilised-iaedes-albopictusi-malesun-0p2S.pdf

De Meeûs, T., J. Bouyer, S. Ravel, and P. Solano. 2015. Ecotype evolution in Glossina palpalis subspecies, major vectors of sleeping sickness. PLOS Neglected Tropical Diseases 9(3): e0003497. https://doi.org/10.1371/journal.pntd.0003497

Devescovi, F., S. Abraham, A. K. P. Roriz, N. Nolazco, R. Castañeda, E. Tadeo, C. Caceres, D. F. Segura, M. T. Vera, I. Joachim-Bravo, N. Canal, and J. Rull. 2014. Ongoing speciation within the Anastrepha fraterculus cryptic species complex: the case of the Andean morphotype. Entomologia Experimentalis et Applicata 152(3): 238-247. https://doi.org/10.1111/eea.12219

Dor, A., and P. Liedo. 2018. Survival ability of Mexican fruit fly males from different strains in presence of the predatory orb-weaving spider Argiope argentata (Araneae: Araneidae). Bulletin of Entomological Research 108: 1-8. https://doi.org/10.1017/S0007485318000275

Dor, A., J. Valle-Mora, S. E. Rodríguez-Rodríguez, and P. Liedo. 2014. Predation of Anastrepha ludens (Diptera: Tephritidae) by Norops serranoi (Reptilia: Polychrotidae): functional response and evasion ability. Environmental Entomology 43: 706-715. https://doi.org/10.1603/EN13281

Dyck, V. A. 2010. Rearing codling moth for the sterile insect technique. FAO Plant Production and Protection Paper 199. FAO, Rome, Italy. http://www-naweb.iaea.org/nafa/ipc/public/ipc-codling-moth-sterile-insect-technique-2010.pdf

Dyck, V., S. Graham, and K. Bloem. 1993. Implementation of the sterile insect release programme to eradicate the codling moth, Cydia pomonella (L.) (Lepidoptera: Olethreutidae), in British Columbia, Canada, pp. 285-297. In Management of insect pests: nuclear and related molecular and genetic techniques. FAO/IAEA International Symposium, 19-23 October 1992, Vienna, Austria. IAEA. https:/www.iaea.org/publications/3782/management-of-insect-pests-nuclear-and-related-molecularand-genetic-techniques

Economopoulos, A. P., Y. Nitzan, and Y. Rossler. 1993. Mass-rearing, quality control, and male-only sterile insect technique application with a pupal color genetic sexing strain of the Mediterranean fruit fly, pp. 267-268. In M. Aluja and P. Liedo (eds.), Fruit flies. Biology and management. SpringerVerlag, New York, NY, USA.

Enkerlin, W. R. 2003. Economics of area-wide SIT control programs, pp. 1-10. In Recent trends on sterile insect technique and area-wide integrated pest management - economic feasibility, control projects, farmer organization and Bactrocera dorsalis complex control study. Research Institute for Subtropics, Naha, Japan. 
(FAO/IAEA) Food and Agriculture Organization of the United Nations/International Atomic Energy Agency. 1992. Laboratory training manual on the use of nuclear techniques in insect research and control. Third edition. IAEA, Vienna, Austria.

http://www-naweb.iaea.org/nafa/ipc/public/El_Lab_training_manual.pdf

(FAO/IAEA) Food and Agriculture Organization of the United Nations/International Atomic Energy Agency. 2006. FAO/IAEA standard operating procedures for mass-rearing tsetse flies. Vienna, Austria. http://www-naweb.iaea.org/nafa/ipc/public/Tsetse_Rearing_SOP_web.pdf

(FAO/IAEA) Food and Agriculture Organization of the United Nations/International Atomic Energy Agency. 2017a. Guideline for packing, shipping, holding and release of sterile flies in areawide fruit fly control programmes. Second edition. J. L. Zavala-López and W. R. Enkerlin (eds.). Rome, Italy. 140 pp. http://www-naweb.iaea.org/nafa/ipc/public/Guideline-for-Packing-Sept2017.pdf

(FAO/IAEA) Food and Agriculture Organization of the United Nations/International Atomic Energy Agency. 2017b. Guidelines for standardised mass rearing of Anopheles mosquitoes. Version 1.0. Vienna, Austria. http://www-naweb.iaea.org/nafa/ipc/public/Guidelines-forstandardised-mass-rearing-of-Anopheles-mosquitoes-v1.0.pdf

(FAO/IAEA) Food and Agriculture Organization of the United Nations/International Atomic Energy Agency. 2018. "The Dashboard" for managers of sterile insect technique production facilities. A mass-rearing metrics and monitoring tool. P. Rendón, A. Aldana and C. Cáceres (eds.). FAO/IAEA, Vienna, Austria. 18 pp.

https://www.iaea.org/sites/default/files/23_mar_2018_corrected_version_mmb_-_19_march_2018_b5.pdf

(FAŌ/IAEA/USDA) Food and Agriculture Organization of the United Nations/International Atomic Energy Agency/United States Department of Agriculture. 2019. Product quality control for sterile mass-reared and released tephritid fruit flies. Version 7.0. IAEA, Vienna, Austria. 148 pp. https://www.iaea.org/sites/default/files/qcv7.pdf

Feigenbaum, A. V. 2004. Total quality control. $4^{\text {th }}$ Edition. McGraw-Hill, New York, USA. 896 pp.

Feldmann, U. 1994. Some quality control parameters used in the rearing of tsetse flies, pp. 13-29. In J. P. R. Ochieng'-Odero (ed.), Techniques of insect rearing for the development of integrated pest and vector management strategies. Second edition. ICIPE Science Press, Nairobi, Kenya.

Fisher, K., and C. Caceres. 2000. A filter rearing system for mass reared genetic sexing strains of Mediterranean fruit fly (Diptera: Tephritidae), pp. 543-550. In K. H. Tan (ed.), Proceedings: AreaWide Control of Fruit Flies and Other Insect Pests. International Conference on Area-Wide Control of Insect Pests, and the $5^{\text {th }}$ International Symposium on Fruit Flies of Economic Importance, 28 May5 June 1998, Penang, Malaysia. Penerbit Universiti Sains Malaysia, Pulau Pinang, Malaysia. http://www-naweb.iaea.org/nafa/ipc/public/Area-wide-control_491-650.pdf

Fisher, W. R. 1983. Quality control of mass-reared Lepidoptera using the fall armyworm, Spodoptera frugiperda (JE Smith), as a model. PhD Thesis, University of Florida, FL, USA.

Flint, H., and J. Merkle. 1984. Pink bollworm: disruption of sexual communication by the release of the Z, Z-isomer of gossyplure. Southwestern Entomologist 9: 58-61.

Fried, M. 1971. Determination of sterile-insect competitiveness. Journal of Economic Entomology 64: 869-872. https://doi.org/10.1093/jee/64.4.869

Fu, H., F. W. Zhu, Y. Y. Deng, Q. F. Weng, M. Y. Hu, and T. Z. Zhang. 2016. Development, reproduction and sexual competitiveness of Conopomorpha sinensis (Lepidoptera: Gracillariidae) gamma-irradiated as pupae and adults. Florida Entomologist 99(Special Issue 1): 66-72. http://journals.fcla.edu/flaent/article/view/88487/84955

González-López, G. I., D. Rao, F. Díaz-Fleischer, D. Orozco-Dávila, and D. Pérez-Staples. 2016. Antipredator behavior of the new mass-reared unisexual strain of the Mexican fruit fly. Bulletin of Entomological Research 106(3): 314-321. https://doi.org/10.1017/S0007485315000966

Gooding, R. H., U. Feldmann, and A. S. Robinson. 1997. Care and maintenance of tsetse colonies, pp. 41-55. In J. M. Crampton, C. B. Beard and C. Louis (eds.), Molecular biology of insect disease vectors: a methods manual. Chapman and Hall Ltd., London, UK.

Haisch, A. 1970. Some observations on decreased vitality of irradiated Mediterranean fruit fly, pp. 7175. Proceedings, Panel: Sterile-Male Technique for Control of Fruit Flies. Joint FAO/IAEA Division of Atomic Energy in Food and Agriculture, 1-5 September 1969, Vienna, Austria. STI/PUB/276. https://www.iaea.org/sites/default/files/ipc-sterile_male-technique-control-fruit-flies.pdf

Hallman, G. J. 2005. Hypoxia reduces reproductive susceptibility of plum curculio (Coleoptera: Curculionidae) to ionizing radiation. Florida Entomologist 88: 208-210. https://doi.org/10.1653/0015-4040(2005)088[0208:HRRSOP]2.0.CO;2 
Hammack, L. 1987. Chemical basis for asymmetric mating isolation between strains of screwworm fly, Cochliomyia hominivorax. Journal of Chemical Ecology 13(6): 1419-1430. https://link.springer.com/article/10.1007/BF01012288

Haq, I., M. J. B. Vreysen, C. Cacéres, T. E. Shelly, and J. Hendrichs. 2014. Methyl eugenol aromatherapy enhances the mating competitiveness of male Bactrocera carambolae Drew \& Hancock (Diptera: Tephritidae). Journal of Insect Physiology 68: 1-6. http://dx.doi.org/10.1016/j.jinsphys.2014.06.014

Haq, I. ul, M. J. B. Vreysen, C. Cacéres, T. E. Shelly, and J. Hendrichs. 2015. Optimizing methyleugenol aromatherapy to maximize posttreatment effects to enhance mating competitiveness of male Bactrocera carambolae (Diptera: Tephritidae). Insect Science 22: 661-669. http://dx.doi.org/10.1111/1744-7917.12148

Haq, I. ul, M. J. B. Vreysen, M. Schutze, J. Hendrichs, and T. Shelly. 2016. Effects of methyl eugenol feeding on mating compatibility of Asian population of Bactrocera dorsalis (Diptera: Tephritidae) with African population and with B. carambolae. Journal of Economic Entomology 109: 148-153. https://dx.doi.org/10.1093/jee/tov274

Haynes, J. W., and J. W. Smith. 1989. 1988 quality assessment of sterile boll weevils. Research Report - Mississippi Agricultural and Forestry Experiment Station (USA) 14: 1-4.

Hendrichs, J., B. I. Katsoyannos, D. R. Papaj, and R. J. Prokopy. 1991. Sex differences in movement between natural feeding and mating sites and tradeoffs between food consumption, mating success and predator evasion in Mediterranean fruit flies (Diptera: Tephritidae). Oecologia 86(2): 223-231. https://link.springer.com/article/10.1007/BF00317534

Hendrichs, J., C. R. Lauzon, S. S. Cooley, and R. J. Prokopy. 1993. Contribution of natural food sources to adult longevity and fecundity of Rhagoletis pomonella (Diptera: Tephritidae). Annals of the Entomological Society of America 86(3): 250-264. https://doi.org/10.1093/aesa/86.3.250

Hendrichs, J., B. I. Katsoyannos, V. Wornoayporn, and M. A. Hendrichs. 1994. Odour-mediated foraging by yellowjacket wasps (Hymenoptera: Vespidae): predation on leks of pheromone-calling Mediterranean fruit fly males (Diptera: Tephritidae). Oecologia 99(1-2): 88-94.

https://link.springer.com/article/10.1007\%2FBF00317087

Hendrichs, J., A. S. Robinson, J. P. Cayol, and W. Enkerlin. 2002. Medfly areawide sterile insect technique programmes for prevention, suppression or eradication: the importance of mating behavior studies. Florida Entomologist 85: 1-13. http://journals.fcla.edu/flaent/article/view/75040/72698

Hendrichs, M. A., and J. Hendrichs. 1998. Perfumed to be killed: interception of Mediterranean fruit fly (Diptera: Tephritidae) sexual signaling by predatory foraging wasps (Hymenoptera: Vespidae). Annals of the Entomological Society of America 91: 228-234. https://doi.org/10.1093/aesa/91.2.228

Hendrichs, M. A., V. Wornoayporn, B. Katsoyannos, and J. Hendrichs. 2007. Quality control method to measure predator evasion in wild and mass-reared Mediterranean fruit flies (Diptera: Tephritidae). Florida Entomologist 90: 64-70. https://www.jstor.org/stable/4151139

Hernández-Ortiz, V., A. F. Bartolucci, P. Morales-Valles, D. Fráas, and D. Selivon. 2012. Cryptic species of the Anastrepha fraterculus complex (Diptera: Tephritidae): a multivariate approach for the recognition of South American morphotypes. Annals of the Entomological Society of America 105: 305-318. https://doi.org/10.1603/AN11123

Hibino, Y., and O. Iwahashi. 1991. Appearance of wild females unreceptive to sterilized males on Okinawa Is. in the eradication program of the melon fly, Dacus cucurbitae Coquillett (Diptera: Tephritidae). Applied Entomology and Zoology 26: 265-270. https://doi.org/10.1303/aez.26.265

Hofmann, H. C. 1985. Methods development activities in Mexico. Miscellaneous Publications of the Entomological Society of America 62: 41-48.

Hooper, G. H. S. 1972. Sterilization of the Mediterranean fruit fly with gamma radiation: effect on male competitiveness and change in fertility of females alternately mated with irradiated and untreated males. Journal of Economic Entomology 65: 1-6. https://doi.org/10.1093/jee/65.1.1

Hooper, G. H. S., and I. F. Horton. 1981. Competitiveness of sterilized male insects: a method of calculating the variance of the value derived from competitive mating tests. Journal of Economic Entomology 74: 119-121. https://doi.org/10.1093/jee/74.1.119

Huettel, M. D. 1976. Monitoring the quality of laboratory-reared insects: a biological and behavioral perspective. Environmental Entomology 5: 807-814. https://doi.org/10.1093/ee/5.5.807

Hunt, M. K., E. A. Roux, R. J. Wood, and A. S. Gilburn. 2002. The effect of supra-fronto-orbital (SFO) bristle removal on male mating success in the Mediterranean fruit fly (Diptera: Tephritidae). Florida Entomologist 85: 83-88. http://journals.fcla.edu/flaent/article/view/75048/72706 
(IAEA) International Atomic Energy Agency. 2012. Quality control for expanded tsetse production, sterilization and field application. IAEA-TECDOC-1683.

https://www-pub.iaea.org/MTCD/Publications/PDF/TE_1683_web.pdf

(ISO) International Organization for Standardization. 2019.

https://www.iso.org/publication/PUB100208.html https://www.iso.org/iso-9001-quality-management.html

Iwahashi, O., Y. Itô, and M. Shiyomi. 1983. A field evaluation of the sexual competitiveness of sterile melon flies, Dacus (Zeugodacus) cucurbitae. Ecological Entomology 8: 43-48. https://doi.org/10.1111/j.1365-2311.1983.tb00481.x

Jang, E. B. 2002. Physiology of mating behavior in Mediterranean fruit fly (Diptera: Tephritidae): chemoreception and male accessory gland fluids in female post-mating behavior. Florida Entomologist 85: 89-93. http://journals.fcla.edu/flaent/article/view/75049/72707

Jang, E. B., D. O. McInnis, R. Kurashima, B. Woods, and D. M. Suckling. 2012. Irradiation of adult Epiphyas postvittana (Lepidoptera: Tortricidae): egg sterility in parental and F1 generations. Journal of Economic Entomology 105: 54-61. https://doi.org/10.1603/EC11135

Ji, Q. E., J. H. Chen, D. O. McInnis, and Q. L. Guo. 2013. The effect of methyl eugenol exposure on subsequent mating performance of sterile males of Bactrocera dorsalis. Journal of Applied Entomology 137(Issue s1): 238-243. https://dx.doi.org/10.1111/j.1439-0418.2011.01686.x

Kaspi, R., and B. Yuval. 2000. Post-teneral protein feeding improves sexual competitiveness but reduces longevity of mass-reared sterile male Mediterranean fruit flies (Diptera: Tephritidae). Annals of the Entomological Society of America 93: 949-955.

https://doi.org/10.1603/0013-8746(2000)093[0949:PTPFIS]2.0.CO;2

Katsoyannos, B. I., N. T. Papadopoulos, J. Hendrichs, and V. Wornoayporn. 1999. Comparative response to citrus foliage and citrus fruit odour by wild and mass-reared sterile Mediterranean fruit fly males of a genetic sexing strain. Journal of Applied Entomology 123(3): 139-143. https://doi.org/10.1046/j.1439-0418.1999.00327.x

Kean, J. M., D. M. Suckling, L. D. Stringer, and B. Woods. 2011. Modeling the sterile insect technique for suppression of light brown apple moth (Lepidoptera: Tortricidae). Journal of Economic Entomology 104: 1462-1475. https://doi.org/10.1603/EC11086

Kleynhans, E., D. E. Conlong, and J. S. Terblanche. 2014. Host plant-related variation in thermal tolerance of Eldana saccharina. Entomologia Experimentalis et Applicata 150(2): 113-122. https://doi.org/10.1111/eea.12144

Knipling, E. F. 1979. The basic principles of insect population suppression and management. Agriculture Handbook Number 512. SEA, USDA, Washington, DC, USA.

Koyama, J., H. Kakinohana, and T. Miyatake. 2004. Eradication of the melon fly, Bactrocera cucurbitae, in Japan: importance of behavior, ecology, genetics, and evolution. Annual Review of Entomology 49: 331-349. https://doi.org/10.1146/annurev.ento.49.061802.123224

Kumano, N., T. Kuriwada, K. Shiromoto, D. Haraguchi, and T. Kohama. 2011a. Prolongation of the effective copulation period by fractionated-dose irradiation in the sweet potato weevil, Cylas formicarius. Entomologia Experimentalis et Applicata 141(2): 129-137. https://doi.org/10.1111/j.1570-7458.2011.01181.x

Kumano, N., T. Kuriwada, K. Shiromoto, D. Haraguchi, and T. Kohama. 2011b. Fractionated irradiation improves the mating performance of the West Indian sweet potato weevil Euscepes postfasciatus. Agricultural and Forest Entomology 13(4): 349-356. https://doi.org/10.1111/j.1461-9563.2011.00528.x

LaChance, L. E., A. C. Bartlett, R. A. Bram, R. J. Gagné, O. H. Graham, D. O. McInnis, C. J. Whitten, and J. A. Seawright. 1982. Mating types in screwworm populations? Science 218(4577): 1142-1143. https://science.sciencemag.org/content/218/4577/1142

Leppla, N. C. 2009. The basics of quality control for insect rearing, pp. 289-306. In J. C. Schneider (ed.), Principles and procedures for rearing high quality insects. Mississippi State University, Mississippi State, MS, USA.

Leppla, N. C., and P. De Clercq. 2019. History of the International Organization for Biological Control Global Working Group on Mass Rearing and Quality Assurance. Journal of Insect Science 19(2): 7. https://doi.org/10.1093/jisesa/iey125

Leppla, N. C., R. H. Guy, D. L. Chambers, and R. B. Workman. 1980. Laboratory colonization of a noctuid moth. Annals of the Entomological Society of America 73: 568-571. https://doi.org/10.1093/aesa/73.5.568 
Leppla, N. C., K. A. Bloem, and R. F. Luck. 2002. Quality control for mass-reared arthropods. Proceedings of the Eighth and Ninth Workshops of the IOBC Working Group on Quality Control of Mass-Reared Arthropods. International Organization for Biological Control.

Liedo, P., S. Salgado, A. Oropeza, and J. Toledo. 2007. Improving mating performance of massreared sterile Mediterranean fruit flies (Diptera: Tephritidae) through changes in adult holding conditions: demography and mating competitiveness. Florida Entomologist 90: 33-40. http://journals.fcla.edu/flaent/article/view/75611/73269

Little, H. F., and R. T. Cunningham. 1978. Missing indirect flight muscles in the Mediterranean fruit fly with droopy wing syndrome. Annals of the Entomological Society of America 71: 517-518. https://doi.org/10.1093/aesa/71.4.517

Little, H. F., R. M. Kobayashi, E. T. Ozaki, and R. T. Cunningham. 1981. Irreversible damage to flight muscles resulting from disturbance of pupae during rearing of the Mediterranean fruit fly, Ceratitis capitata. Annals of the Entomological Society of America 74: 24-26. https://doi.org/10.1093/aesa/74.1.24

Lopez, G. I., R. Courtis, G. L. Hernandez, C. Bajatta, C. Hofmann, and M. Y. Perez. 1995. Manual de operacion de control de calidad del insecto Cochliomyia hominivorax. Departamento de Control de Calidad, Unidad de Calidad del Insecto, Comision Mexico Americana para la Erradicacion del Gusano Barrenador del Ganado, Chiapas, Mexico.

López-Martínez, G., J. E. Carpenter, S. D. Hight, and D. A. Hahn. 2014. Low-oxygen atmospheric treatment improves the performance of irradiation-sterilized male cactus moths used in SIT. Journal of Economic Entomology 107: 185-197. https://doi.org/10.1603/EC13370

López-Martínez, G., J. E. Carpenter, S. D. Hight, and D. A. Hahn. 2016. Anoxia-conditioning hormesis alters the relationship between irradiation doses for survival and sterility in the cactus moth, Cactoblastis cactorum (Lepidoptera: Pyralidae). Florida Entomologist 99(Special Issue 1): 95-104. http://journals.fcla.edu/flaent/article/view/88491/84959

Mackauer, M. 1976. Genetic problems in the production of biological control agents. Annual Review of Entomology 21: 369-385. https://doi.org/10.1146/annurev.en.21.010176.002101

Mangan, R. L. 1992. Evaluating the role of genetic change in insect colonies maintained for pest management, pp. 269-288. In T. E. Anderson and N. C. Leppla (eds.), Advances in insect rearing for research and pest management. Westview Press, Boulder, CO, USA.

Maor, M., B. Kamensky, S. Shloush, and B. Yuval. 2004. Effects of post-teneral diet on foraging success of sterile male Mediterranean fruit flies. Entomologia Experimentalis et Applicata 110(3): 225-230. https://doi.org/10.1111/j.0013-8703.2004.00139.x

McBrien, H. L., and G. J. R. Judd. 1996. A Teflon ${ }^{\circledR}$-walled mating table for assessing pheromonebased mating disruption. Journal of the Entomological Society of British Columbia 93: 121-125. https://journal.entsocbc.ca/index.php/journal/article/view/529/538

McGovern, W. L., G. H. McKibben, R. C. Gueldner, and W. H. Cross. 1975. Irradiated boll weevils: pheromone production determined by GLC analysis. Journal of Economic Entomology 68: 521-523. https://doi.org/10.1093/jee/68.4.521

McInnis, D. O., D. R. Lance, and C. G. Jackson. 1996. Behavioral resistance to the sterile insect technique by Mediterranean fruit fly (Diptera: Tephritidae) in Hawaii. Annals of the Entomological Society of America 89: 739-744. https://doi.org/10.1093/aesa/89.5.739

McInnis, D. O., P. Rendon, and J. Komatsu. 2002. Mating and remating of medflies (Diptera: Tephritidae) in Guatemala: individual fly marking in field cages. Florida Entomologist 85: 126-137. http://journals.fcla.edu/flaent/article/view/75053/72711

Meza, J. S., J. Arredondo, D. Orozco, and D. Pérez-Staples. 2014. Disparity in sexual behaviour between wild and mass-reared Mexican fruit flies. Physiological Entomology 39(3): 263-270. https://doi.org/10.1111/phen.12071

Minks, A. K. 1971. Decreased sex pheromone production in an in-bred stock of the summerfruit tortrix moth, Adoxophyes orana. Entomologia Experimentalis et Applicata 14(3): 361-364. https://doi.org/10.1111/j.1570-7458.1971.tb00173.x

Miyatake, T. 1993. Difference in the larval and pupal periods between mass-reared and wild strains of the melon fly, Bactrocera cucurbitae (Coquillett) (Diptera: Tephritidae). Applied Entomology and Zoology 28: 577-581. https://doi.org/10.1303/aez.28.577

Miyatake, T. 1995. Two-way artificial selection for developmental period in Bactrocera cucurbitae (Diptera: Tephritidae). Annals of the Entomological Society of America 88: 848-855. https://doi.org/10.1093/aesa/88.6.848 
Miyatake, T. 1996. Comparison of adult life history traits in lines artificially selected for long and short larval and pupal developmental periods in the melon fly, Bactrocera cucurbitae (Diptera: Tephritidae). Applied Entomology and Zoology 31: 335-343. https://doi.org/10.1303/aez.31.335

Miyatake, T. 1997a. Correlated responses to selection for developmental period in Bactrocera cucurbitae (Diptera: Tephritidae): time of mating and daily activity rhythms. Behavior Genetics 27(5): 489-498. https://link.springer.com/article/10.1023/A\%3A1025682618895

Miyatake, T. 1997b. Genetic trade-off between early fecundity and longevity in Bactrocera cucurbitae (Diptera: Tephritidae). Heredity 78: 93-100.

Miyatake, T. 1998a. Genetic changes of life history and behavioral traits during mass-rearing in the melon fly, Bactrocera cucurbitae (Diptera: Tephritidae). Researches on Population Ecology 40: 301310. http://meme.biology.tohoku.ac.jp/POPECOL/RPcontents/AB40\%283\%29.html\#anchor1 104092

Miyatake, T. 1998b. Genetic variation in pre-mating period of the mass-reared melon fly, Bactrocera cucurbitae (Diptera: Tephritidae). Appl. Ent. Zool. 33: 29-33. https://doi.org/10.1303/aez.33.29

Miyatake, T. 2002. Circadian rhythm and time of mating in Bactrocera cucurbitae (Diptera: Tephritidae) selected for age at reproduction. Heredity 88: 302-306.

Miyatake, T., and D. Haraguchi. 1996. Mating success in Bactrocera cucurbitae (Diptera: Tephritidae) under different rearing densities. Annals of the Entomological Society of America 89: 284-289. https://doi.org/10.1093/aesa/89.2.284

Miyatake, T., and T. Shimizu. 1999. Genetic correlations between life-history and behavioral traits can cause reproductive isolation. Evol. 53: 201-208. https://doi.org/10.1111/j.1558-5646.1999.tb05345.x

Miyatake, T., and M. Yamagishi. 1999. Rapid evolution of larval development time during massrearing in the melon fly, Bactrocera cucurbitae. Researches on Population Ecology 41: 291-297. https://link.springer.com/article/10.1007/s101440050034

Miyatake, T., A. Matsumoto, T. Matsuyama, H. R. Ueda, T. Toyosato, and T. Tanimura. 2002. The period gene and allochronic reproductive isolation in Bactrocera cucurbitae. Proceedings of the Royal Society B: Biological Sciences 269(1508): 2467-2472. https://doi.org/10.1098/rspb.2002.2152

(MRQA/IOBC) Mass Rearing and Quality Assurance Working Group/International Organization for Biological Control. 2019. http://www.mrqa.unibo.it/

Mudavanhu, P., P. Addison, and D. E. Conlong. 2014. Impact of mass rearing and gamma irradiation on thermal tolerance of Eldana saccharina. Entomologia Experimentalis et Applicata 153(1): 55-63. https://doi.org/10.1111/eea.12228

Mudavanhu, P., P. Addison, J. E. Carpenter, and D. E. Conlong. 2016. Mating compatibility and competitiveness between wild and laboratory strains of Eldana saccharina (Lepidoptera: Pyralidae) after radiation treatment. Florida Entomologist 99(Special Issue 1): 54-65. http://journals.fcla.edu/flaent/article/view/88486/84954

Mutika, G. N., E. Opiyo, and A. S. Robinson. 2001. Assessing mating performance of male Glossina pallidipes (Diptera: Glossinidae) using a walk-in field cage. Bulletin of Entomological Research 91(4): 281-287. https://doi.org/10.1079/BER2001102

Mutika, G. N., E. Opiyo, and A. S. Robinson. 2002. Effect of low temperature treatment on the quality of male adult Glossina pallidipes (Diptera: Glossinidae) in relation to the sterile insect technique. Entomological Science 5: 209-214.

Mutika, G. N., I. Kabore, M. T. Seck, B. Sall, J. Bouyer, A. G. Parker, and M. J. B. Vreysen. 2013. Mating performance of Glossina palpalis gambiensis strains from Burkina Faso, Mali, and Senegal. Entomologia Experimentalis et Applicata 146(1, Special Issue): 177-185. https://doi.org/10.1111/j.1570-7458.2012.01305.x

Nakamori, H., and H. Soemori. 1981. Comparison of dispersal ability and longevity for wild and mass-reared melon flies: Dacus cucurbitae Coquillett (Diptera: Tephritidae), under field conditions. Applied Entomology and Zoology 16: 321-327. https://doi.org/10.1303/aez.16.321

Nei, M., T. Maruyama, and R. Chakraborty. 1975. The bottleneck effect and genetic variability in populations. Evolution 29: 1-10. https://doi.org/10.1111/j.1558-5646.1975.tb00807.x

Nelson, R. L., and M. M. Milby. 1980. Dispersal and survival of field and laboratory strains of Culex tarsalis (Diptera: Culicidae). J. Med. Ent. 17: 146-150. https://doi.org/10.1093/jmedent/17.2.146

Obra, G. B., and S. S. Resilva. 2013. Influence of adult diet and exposure to methyl eugenol in the mating performance of Bactrocera philippinensis. Journal of Applied Entomology 137(Issue s1): 210-216. https://dx.doi.org/10.1111/j.1439-0418.2011.01678.x

Ochieng'-Odero, J. P. R. 1994. Does adaptation occur in insect rearing systems, or is it a case of selection, acclimatization and domestication? Insect Science and Its Application 15: 1-7. https://doi.org/10.1017/S1742758400016696 
Ohinata, K., M. Ashraf, and E. J. Harris. 1977. Mediterranean fruit flies: sterility and sexual competitiveness in the laboratory after treatment with gamma irradiation in air, carbon dioxide, helium, nitrogen or partial vacuum. J. Econ. Ent. 70: 165-168. https://doi.org/10.1093/jee/70.2.165

Oliva, C. F., M. Jacquet, J. Gilles, G. Lemperiere, P.-O. Maquart, S. Quilici, F. Schooneman, M. J. B. Vreysen, and S. Boyer. 2012. The sterile insect technique for controlling populations of Aedes albopictus (Diptera: Culicidae) on Reunion Island: mating vigour of sterilized males. PLOS ONE 7(11): e49414. https://www.ncbi.nlm.nih.gov/pmc/articles/PMC3504010/

Opiyo, E. 2001. Survival and reproductive potential of gamma irradiated male Glossina pallidipes Austen. Entomologia Experimentalis et Applicata 99(3): 397-400. https://doi.org/10.1046/j.1570-7458.2001.00841.x

Orozco, D., and R. O. Lopez. 1993. Mating competitiveness of wild and laboratory mass-reared medflies: effect of male size, pp. 185-188. In M. Aluja and P. Liedo (eds.), Fruit flies. Biology and management. Springer-Verlag, New York, NY, USA.

Orozco-Dávila, D., A. Schwarz-Gehrke, and A. Perez-Romero. 1983. Mediterranean fruit fly quality control procedures manual (in Spanish). Programa Moscamed, Metapa, Dirección General de Sanidad Vegetal, Secretaria de Agricultura y Recursos Hidráulicos. Chiapas, Mexico. 137 pp.

Orozco-Dávila, D., T. Artiaga-López, M. D. R. Hernández, J. Domínguez, and E. Hernández. 2014. Anastrepha obliqua (Diptera: Tephritidae) mass-rearing: effect of relaxed colony management. International Journal of Tropical Insect Science 34(Issue S1): S19-S27. https://doi.org/10.1017/S1742758414000058

Pagabeleguem, S., M. T. Seck, B. Sall, M. J. B. Vreysen, G. Gimonneau, A. G. Fall, M. Bassene, I. Sidibé, J. B. Rayaissé, A. M. G. Belem, and J. Bouyer. 2015. Long distance transport of irradiated male Glossina palpalis gambiensis pupae and its impact on sterile male yield. Parasites and Vectors 8: 259. https://doi.org/10.1186/s13071-015-0869-3

Pagabeleguem, S., S. Ravel, A. H. Dicko, M. J. B. Vreysen, A. Parker, P. Takac, K. Huber, I. Sidibé, G. Gimonneau, and J. Bouyer. 2016. Influence of temperature and relative humidity on survival and fecundity of three tsetse strains. Para. \& Vect. 9: 520. https://doi.org/10.1186/s13071-016-1805-x

Pagendam, D., N. Snoad, W. H. Yang, M. Segoli, S. Ritchie, B. Trewin, and N. Beebe. 2018. Improving estimates of Fried's index from mating competitiveness experiments. J. Agric., Biological and Environ. Statistics 23: 446-462. https://link.springer.com/article/10.1007/s13253-018-0333-x

Parker, A., and K. Mehta. 2007. Sterile insect technique: a model for dose optimization for improved sterile insect quality. Florida Ent. 90: 88-95. http://journals.fcla.edu/flaent/article/view/75618/73276

Parker, F. D., and J. B. Welch. 1991. Alternative to sentinel animals for collecting egg masses from wild females of the screw worm (Diptera: Calliphoridae). Journal of Economic Entomology 84(5): 1476-1479. https://doi.org/10.1093/jee/84.5.1476

Parsons, P. A. 1974. Male mating speed as a component of fitness in Drosophila. Behavior Genetics 4(4): 395-404. https://link.springer.com/article/10.1007/BF01066159

Pashley, D. P., and M. D. Proverbs. 1981. Quality control by electrophoretic monitoring in a laboratory colony of codling moths. Annals of the Entomological Society of America 74: 20-23. https://doi.org/10.1093/aesa/74.1.20

Pendlebury, W. W., and J. F. Kidwell. 1974. The effect of inbreeding on male mating ability in Drosophila melanogaster. Theoretical and Applied Genetics 44: 128. https://link.springer.com/article/10.1007/BF02981925

Pérez-Staples, D., T. E. Shelly, and B. Yuval. 2013. Female mating failure and the failure of 'mating' in sterile insect programs. Entomologia Experimentalis et Applicata 146(1, Special Issue): 66-78. https://doi.org/10.1111/j.1570-7458.2012.01312.x

Proverbs, M. D., and J. R. Newton. 1962. Influence of gamma radiation on the development and fertility of the codling moth, Carpocapsa pomonella (L.) (Lepidoptera: Olethreutidae). Canadian Journal of Zoology 40(3): 401-420. https://doi.org/10.1139/z62-038

Quintero-Fong, L., J. Toledo, L. Ruiz-Montoya, P. Rendón, D. Orozco-Dávila, J. Valle-Mora, and P. Liedo. 2018. Demography of a genetic sexing strain of Anastrepha ludens (Diptera: Tephritidae): effects of selection based on mating performance. Agricultural and Forest Entomology 20: 1-8. https://doi.org/10.1111/afe.12223

Rajagopalan, P. K., M. Yasuno, and G. C. Labrecque. 1973. Dispersal and survival in the field of chemosterilized, irradiated, and cytoplasmically incompatible male Culex pipiens fatigans. Bulletin of the WHO 48(5): 631-635. https://www.ncbi.nlm.nih.gov/pmc/articles/PMC2482925/ 
Rathnayake, D. N., E. C. Lowe, P. Rempoulakis, and M. E. Herberstein. 2019. Effect of natural predators on Queensland fruit fly, Bactrocera tryoni (Froggatt) (Diptera: Tephritidae) control by sterile insect technique (SIT). Pest Management Science 75(12): 3356-3362. https://onlinelibrary.wiley.com/doi/abs/10.1002/ps.5477

Raulston, J. R., H. M. Graham, P. D. Lingren, and J. W. Snow. 1976. Mating interaction of native and laboratory-reared tobacco budworms released in the field. Environmental Entomology 5: 195198. https://doi.org/10.1093/ee/5.1.195

Reisen, W. K., R. K. Sakai, R. H. Baker, H. R. Rathor, K. Raana, K. Azra, and S. Niaz. 1980. Field competitiveness of Culex tritaeniorhynchus Giles males carrying a complex chromosomal aberration: a second experiment. Ann. Entomol. Soc. Amer. 73: 479-484. https://doi.org/10.1093/aesa/73.4.479

Rendón, P., D. McInnis, D. Lance, and J. Stewart. 2000. Comparison of medfly male-only and bisexual releases in large scale field trials, pp. 517-525. In K. H. Tan (ed.), Proceedings: Area-Wide Control of Fruit Flies and Other Insect Pests. International Conference on Area-Wide Control of Insect Pests, and the $5^{\text {th }}$ International Symposium on Fruit Flies of Economic Importance, 28 May-5 June 1998, Penang, Malaysia. Penerbit Universiti Sains Malaysia, Pulau Pinang, Malaysia. http://www-naweb.iaea.org/nafa/ipc/public/Area-wide-control_491-650.pdf

Rendón, P., D. McInnis, D. Lance, and J. Stewart. 2004. Medfly (Diptera: Tephritidae) genetic sexing: large-scale field comparison of males-only and bisexual sterile fly releases in Guatemala. Journal of Economic Entomology 97: 1547-1553. https://doi.org/10.1603/0022-0493-97.5.1547

Resilva, S. S., and R. Pereira. 2014. Age- and temperature-related pupal eye colour changes in various tephritid fruit fly species with a view to optimizing irradiation timing. International Journal of Tropical Insect Science 34(Issue S1): S59-S65. https://doi.org/10.1017/S1742758414000095

Resilva, S. S., E. Hernández, and G. B. Obra. 2019. Radiation sterilization of Mexican fruit fly Anastrepha ludens (Leow) based on pupal eye color. Philippine Journal of Science 148: 45-50. http://philjournalsci.dost.gov.ph/home-1/83-vol-148-no-1-march-2019/875-radiation-sterilization-ofmexican-fruit-fly-anastrepha-ludens-leow-based-on-pupal-eye-color

Richmond, J. A., and C. W. Berisford. 1980. Comparison of attraction of pheromone extracts from diet-reared and wild Rhyacionia frustrana females to wild males. Journal of the Georgia Entomological Society 15: 258-260.

Robinson, A. S. 1975. Influence of anoxia during gamma irradiation on the fertility and competitiveness of the adult male codling moth, Laspeyresia pomonella. Radiation Research 61(3): 526-534. https://doi.org/10.2307/3574127

Robinson, A. S., G. Franz, and K. Fisher. 1999. Genetic sexing strains in the medfly, Ceratitis capitata: development, mass rearing and field application. Trends in Entomology 2: 81-104. http://www.researchtrends.net/tia/abstract.asp?in=0\&vn=2\&tid=20\&aid=684\&pub=1999\&type=3

Rössler, Y. 1975a. The ability to inseminate: a comparison between laboratory-reared and field populations of the Mediterranean fruitfly (Ceratitis capitata). Entomologia Experimentalis et Applicata 18(2): 255-257. https://doi.org/10.1111/j.1570-7458.1975.tb02377.x

Rössler, Y. 1975b. Reproductive differences between laboratory-reared and field-collected populations of the Mediterranean fruitfly, Ceratitis capitata. Annals of the Entomological Society of America 68: 987-991. https://doi.org/10.1093/aesa/68.6.987

Rössler, Y. 1980. Sexual competitiveness of males of the Mediterranean fruitfly, Ceratitis capitata (Wiedemann) (Diptera: Tephritidae), carrying a Y-chromosome translocation. Bulletin of Entomological Research 70(4): 649-656. https://doi.org/10.1017/S0007485300007938

Ruhm, M. E., and C. O. Calkins. 1981. Eye-color changes in Ceratitis capitata pupae, a technique to determine pupal development. Entomologia Experimentalis et Applicata 29(2): 237-240. https://doi.org/10.1111/j.1570-7458.1981.tb03064.x

Rull, J., A. Birke, R. Ortega, P. Montoya, and L. López. 2012. Quantity and safety vs. quality and performance: conflicting interests during mass rearing and transport affect the efficiency of sterile insect technique programs. Entomologia Experimentalis et Applicata 142: 78-86. https://doi.org/10.1111/j.1570-7458.2011.01196.x

Saour, G. 2014. Sterile insect technique and $F_{1}$ sterility in the European grapevine moth, Lobesia botrana. Journal of Insect Science 14: 8. https://doi.org/10.1093/jis/14.1.8

Saour, G. 2016. Flight ability and dispersal of European grapevine moth gamma-irradiated males (Lepidoptera: Tortricidae). Florida Entomologist 99(Special Issue 1): 73-78. http://journals.fcla.edu/flaent/article/view/88488/84956

Seck, M. T., S. Pagabeleguem, M. D. Bassene, A. G. Fall, T. A. R. Diouf, B. Sall, M. J. B. Vreysen, J. B. Rayaissé, P. Takac, I. Sidibé, A. G. Parker, G. N. Mutika, J. Bouyer, and G. Gimonneau. 
2015. Quality of sterile male tsetse after long distance transport as chilled, irradiated pupae. PLOS Neglected Tropical Diseases 9(11): e0004229. https://doi.org/10.1371/journal.pntd.0004229

Segura, D. F., M. T. Vera, J. Rull, V. Wornoayporn, A. Islam, and A. S. Robinson. 2011. Assortative mating among Anastrepha fraterculus (Diptera: Tephritidae) hybrids as a possible route to radiation of the fraterculus cryptic species complex. Biological Journal of the Linnean Society 102(2): 346-354. https://doi.org/10.1111/j.1095-8312.2010.01590.x

Serghiou, C. S. 1977. Selected factors affecting the quality of Mediterranean fruit fly used in sterile release programs. J. of Economic Entomology 70: 351-356. https://doi.org/10.1093/jee/70.3.351

Seth, R. K., Z. Khan, D. K. Rao, and M. Zarin. 2016. Appraisal of sperm dynamics as a crucial trait of radiosterilized Spodoptera litura (Lepidoptera: Noctuidae) and its $F_{1}$ progeny for evaluation of the 'inherited sterility technique' for pest suppression. Florida Entomologist 99(Special Issue 1): 105118. http://journals.fcla.edu/flaent/article/view/88492/84960

Sharp, J. 1976. Comparison of flight ability of wild-type and laboratory-reared Caribbean fruit flies on a flight mill. Journal of the Georgia Entomological Society 11:255-258.

Sharp, J. L., and H. F. Little. 1982. Effect of mechanical disturbance on median dorsal flight muscle development of Anastrepha suspensa. Annals of the Entomological Society of America 75: 146-149. https://doi.org/10.1093/aesa/75.2.146

Sharp, J. L., T. C. Carlysle, and H. F. Little. 1980. Missing indirect flight muscles in Anastrepha suspensa with droopy wing syndrome. Annals of the Entomological Society of America 73: 239-243. https://doi.org/10.1093/aesa/73.2.239

Shelly, T. E. 1995. Methyl eugenol and the mating competitiveness of irradiated male Bactrocera dorsalis (Diptera: Tephritidae). Annals of the Entomological Society of America 88: 883-886. https://doi.org/10.1093/aesa/88.6.883

Shelly, T. E., S. S. Kennelly, and D. O. McInnis. 2002. Effect of adult diet on signaling activity, mate attraction, and mating success in male Mediterranean fruit flies (Diptera: Tephritidae). Florida Entomologist 85: 150-155. http://journals.fcla.edu/flaent/article/view/75056/72714

Shimoji, Y., and T. Miyatake. 2002. Adaptation to artificial rearing during successive generations in the West Indian sweetpotato weevil, Euscepes postfasciatus (Coleoptera: Curculionidae). Ann. Ent. Soc. Amer. 95: 735-739. https://doi.org/10.1603/0013-8746(2002)095[0735:ATARDS]2.0.CO;2

Simmons, G. S., D. M. Suckling, J. E. Carpenter, M. F. Addison, V. A. Dyck, and M. J. B. Vreysen. 2010. Improved quality management to enhance the efficacy of the sterile insect technique for lepidopteran pests. Journal of Applied Entomology 134(3): 261-273. https://doi.org/10.1111/j.1439-0418.2009.01438.x

Singh, D. 2018. What is the difference between quality control and quality assurance? Quora (25 Jan.). https://www.quora.com/What-is-the-difference-between-quality-control-and-quality-assurance-1

Sivinski, J., C. O. Calkins, and J. C. Webb. 1989. Comparisons of acoustic courtship signals in wild and laboratory reared Mediterranean fruit fly Ceratitis capitata. Scientific Notes. Florida Entomologist 72: 212-214. http://journals.fcla.edu/flaent/article/view/58471/56150

Smith, P. H., C. A. Konovalov, G. G. Foster, and R. W. Kerr. 1981. Assessment of the quality of mass-reared Lucilia cuprina (Wiedemann) (Diptera: Calliphoridae) males treated with dieldrin as larvae in a female-killing procedure. Bulletin of Entomological Research 71: 1-10. https://doi.org/10.1017/S0007485300050975

Snow, J. W., J. R. Raulston, and F. S. Guillot. 1976. Mating tables: a method of studying the mating and the competitive behavior of Lepidoptera and Diptera in the field. Annals of the Entomological Society of America 69(4): 751-752. https://doi.org/10.1093/aesa/69.4.751

Soopaya, R., L. D. Stringer, B. Woods, A. E. A. Stephens, R. C. Butler, I. Lacey, A. Kaur, and D. M. Suckling. 2011. Radiation biology and inherited sterility of light brown apple moth (Lepidoptera: Tortricidae): developing a sterile insect release program. Journal of Economic Entomology 104: 1999-2008. https://doi.org/10.1603/EC11049

Sow, A., I. Sidibé, Z. Bengaly, A. Z. Bancé, G. J. Sawadogo, P. Solano, M. J. B. Vreysen, R. Lancelot, and J. Bouyer. 2012. Irradiated male tsetse from a 40 -year-old colony are still competitive in a riparian forest in Burkina Faso. PLOS ONE 7(5): e37124. https://doi.org/10.1371/journal.pone.0037124

Sower, L. L., D. W. Hagstrum, and J. S. Long. 1973. Comparison of the female pheromones of a wild and a laboratory strain of Cadra cautella, and male responsiveness to the pheromone extracts. Annals of the Entomological Society of America 66: 484-485. https://doi.org/10.1093/aesa/66.2.484

Spates, Jr., G. E., and B. G. Hightower. 1967. Sexual aggressiveness of male screw-worm flies affected by laboratory rearing. J. Econ. Entomol. 60: 752-755. https://doi.org/10.1093/jee/60.3.752 
Spates, Jr., G. E., and B. G. Hightower. 1970. Variations in the size and reproductive capacity of wildtype and laboratory-adapted populations of the screw-worm fly. Journal of Economic Entomology 63: 1381-1385. https://doi.org/10.1093/jee/63.5.1381

Spencer, J., and B. Fujita. 1997. A procedural manual for mass rearing four species of tephritid fruit flies. USDA-ARS, Honolulu, Hawaii, USA.

Stock, M. W., and J. L. Robertson. 1982. Quality assessment and control in a western spruce budworm laboratory colony. Entomologia Experimentalis et Applicata 32(1): 28-32. https://doi.org/10.1111/j.1570-7458.1982.tb03177.x

Stotter, R. L., and J. S. Terblanche. 2009. Low-temperature tolerance of false codling moth Thaumatotibia leucotreta (Meyrick) (Lepidoptera: Tortricidae) in South Africa. Journal of Thermal Biology 34(6): 320-325. https://doi.org/10.1016/j.jtherbio.2009.05.002

Stringer, L. D., N. J. Sullivan, T. E. S. Sullivan, V. J. Mitchell, L. A. M. Manning, F. Mas, R. C. Hood-Nowotny, and D. M. Suckling. 2013. Attractiveness and competitiveness of irradiated light brown apple moths. Ent. Exper. et Applicata 148(3): 203-212. https://doi.org/10.1111/eea.12096

Suckling, D. M., L. D. Stringer, V. J. Mitchell, T. E. S. Sullivan, N. J. Sullivan, G. S. Simmons, A. M. Barrington, and A. M. El-Sayed. 2011. Comparative fitness of irradiated light brown apple moths (Lepidoptera: Tortricidae) in a wind tunnel, hedgerow, and vineyard. Journal of Economic Entomology 104: 1301-1308. https://doi.org/10.1603/EC10394

Tan, L. T., and K. H. Tan. 2013. Automated tephritid fruit fly semiochemical mass feeding structure: design, construction and testing. Journal of Applied Entomology 137(Issue s1): 217-229. https://dx.doi.org/10.1111/j.1439-0418.2011.01680.x

Taret, G., M. Sevilla, V. Wornoayporn, A. Islam, S. Ahmad, C. Caceres, A. S. Robinson, and M. J. B. Vreysen. 2010. Mating compatibility among populations of codling moth Cydia pomonella Linnaeus (Lepidoptera: Tortricidae) from different geographic origins. Journal of Applied Entomology 134(3): 207-215. https://doi.org/10.1111/j.1439-0418.2008.01375.x

Taylor, P. W., and B. Yuval. 1999. Postcopulatory sexual selection in Mediterranean fruit flies: advantages for large and protein-fed males. Animal Behaviour 58(2): 247-254. https://doi.org/10.1006/anbe.1999.1137

Tejeda, M. T., J. Arredondo-Gordillo, D. Orozco-Dávila, L. Quintero-Fong, and F. Díaz-Fleischer. 2017. Directional selection to improve the sterile insect technique: survival and sexual performance of desiccation resistant Anastrepha ludens strains. Evolutionary Applications 10(10): 1020-1030. https://doi.org/10.1111/eva.12506

Timischl, W. 1980. On a statistical control model for the mass rearing of tsetse flies [in German]. Zeitschrift für Angewandte Zoologie 67: 365-376.

Toledo, J., J. Rull, A. Oropeza, E. Hernández, and P. Liedo. 2004. Irradiation of Anastrepha obliqua (Diptera: Tephritidae) revisited: optimizing sterility induction. Journal of Economic Entomology 97: 383-389. https://doi.org/10.1093/jee/97.2.383

Vale, G. A., J. W. Hargrove, A. M. Jordan, P. A. Langley, and A. R. Mews. 1976. Survival and behaviour of tsetse flies (Diptera, Glossinidae) released in the field: a comparison between wild flies and animal-fed and in vitro-fed laboratory-reared flies. Bulletin of Entomological Research 66(4): 731-744. https://doi.org/10.1017/S0007485300010786

Van Keymeulen, M., L. Hertveldt, and C. Pelerents. 1981. Methods for improving both the quantitative and qualitative aspects of rearing Delia brassicae for sterile release programmes. Ent. Experimentalis et Applicata 30(3): 231-240. https://doi.org/10.1111/j.1570-7458.1981.tb03106.x

Vera, M. T., R. J. Wood, J. L. Cladera, and A. S. Gilburn. 2002. Factors affecting female remating frequency in the Mediterranean fruit fly (Diptera: Tephritidae). Florida Entomologist 85: 156-164. http://journals.fcla.edu/flaent/article/view/75057/72715

Villavaso, E. J., E. P. Lloyd, P. S. Lue, and J. E. Wright. 1980. Boll weevils: competitiveness of sterile males in isolated field plots. J. Econ. Ent. 73: 213-217. https://doi.org/10.1093/jee/73.2.213

Vreysen, M. J. B., and A. M. V. Van Der Vloedt. 1995. Radiation sterilization of Glossina tachinoides Westw. pupae. I. The effect of dose fractionation and nitrogen during irradiation in the mid-pupal phase. Revue d'Élevage et de Médecine Vétérinaire des Pays Tropicaux 48: 45-51. http://revues.cirad.fr/index.php/REMVT/article/view/9487/9481

Vreysen, M. J. B., H. J. Barclay, and J. Hendrichs. 2006. Modeling of preferential mating in areawide control programs that integrate the release of strains of sterile males only or both sexes. Ann. Ent.. Soc. Amer. 99: 607-616. https://doi.org/10.1603/0013-8746(2006)99[607:MOPMIA]2.0.CO;2

Vreysen, M. J. B., J. Gerardo-Abaya, and J. P. Cayol. 2007. Lessons from area-wide integrated pest management (AW-IPM) programmes with an SIT component: an FAO/IAEA perspective, pp. 723- 
744. In M. J. B. Vreysen, A. S. Robinson and J. Hendrichs (eds.), Area-wide control of insect pests. From research to field implementation. Springer, Dordrecht, The Netherlands.

https://www.iaea.org/sites/default/files/area-wide-control-insect-pests-book.pdf

Vreysen, M. J. B., K. M. Saleh, R. Lancelot, and J. Bouyer. 2011. Factory tsetse flies must behave like wild flies: a prerequisite for the sterile insect technique. PLOS Neglected Tropical Diseases 5(2): e907. https://doi.org/10.1371/journal.pntd.0000907

Vreysen, M. J. B., W. Klassen, and J. E. Carpenter. 2016. Overview of technological advances toward greater efficiency and efficacy in sterile insect-inherited sterility programs against moth pests. Florida Entomologist 99(Sp. Issue 1): 1-12. http://journals.fcla.edu/flaent/article/view/88480/84948

Walton, A. J., and D. E. Conlong. 2016a. General biology of Eldana saccharina (Lepidoptera: Pyralidae): a target for the sterile insect technique. Florida Entomologist 99(Special Issue 1): 30-35. http://journals.fcla.edu/flaent/article/view/88483/84951

Walton, A. J., and D. E. Conlong. 2016b. Radiation biology of Eldana saccharina (Lepidoptera: Pyralidae). Fl. Ent. 99(Sp. Issue 1): 36-42. http://journals.fcla.edu/flaent/article/view/88484/84952

White, L. D., and R. B. Hutt. 1975. Codling moth: catches of irradiated and untreated laboratory-reared and native males in synthetic sex attractant traps. Journal of Economic Entomology 68: 449-450. https://doi.org/10.1093/jee/68.4.449

White, L. D., and K. D. Mantey. 1977. Codling moth: mating of irradiated and unirradiated laboratoryreared and native moths in the field. J. Econ. Ent. 70: 811-812. https://doi.org/10.1093/jee/70.6.811

White, L. D., M. Koslinska, and Z. W. Suski. 1977. Codling moth: field-cage mating competitiveness of radiosterilized males. J. of Economic Entomology 70: 64-65. https://doi.org/10.1093/jee/70.1.64

Wong, T. T. Y., H. M. Couey, and J. I. Nishimoto. 1982. Oriental fruit fly: sexual development and mating response of laboratory-reared and wild flies. Annals of the Entomological Society of America 75: 191-194. https://doi.org/10.1093/aesa/75.2.191

Woods, B., D. McInnis, E. Steiner, A. Soopaya, J. Lindsey, I. Lacey, A. Virdi, and R. Fogliani. 2016. Developing field cage tests to measure mating competitiveness of sterile light brown apple moths (Lepidoptera: Tortricidae) in Western Australia. Florida Entomologist 99(Special Issue 1): 138-145. http://journals.fcla.edu/flaent/article/view/88495/84963

Wyss, J. 2002. Overview of the sterile insect technique in screw-worm fly eradication, pp. 176-181. Proceedings of the Screw-Worm Fly Emergency Preparedness Conference, 12-15 November 2001, Canberra, Australia. Agriculture, Fisheries and Forestry, Canberra, Australia.

Yamada, H., H. Maiga, J. Juarez, D. De Oliveira Carvalho, W. Mamai, A. Ali, N. S. BimbileSomda, A. G. Parker, D. Zhang, and J. Bouyer. 2019. Identification of critical factors that significantly affect the dose-response in mosquitoes irradiated as pupae. Parasites and Vectors 12: 435. https://doi.org/10.1186/s13071-019-3698-y

Young, J. R., J. W. Snow, J. J. Hamm, W. D. Perkins, and D. G. Haile. 1975. Increasing the competitiveness of laboratory-reared corn earworm by incorporation of indigenous moths from the area of sterile release. Ann. Entomol. Soc. Amer. 68: 40-42. https://doi.org/10.1093/aesa/68.1.40

Yuval, B., R. Kaspi, S. A. Field, S. Blay, and P. Taylor. 2002. Effects of post-teneral nutrition on reproductive success of male Mediterranean fruit flies (Diptera: Tephritidae). Florida Entomologist 85: 165-170. http://journals.fcla.edu/flaent/article/view/75058/72716

Yuval, B., M. Maor, K. Levy, R. Kaspi, P. Taylor, and T. Shelly. 2007. Breakfast of champions or kiss of death? Survival and sexual performance of protein-fed, sterile Mediterranean fruit flies (Diptera: Tephritidae). Fl. Ent. 90: 115-122. http://journals.fcla.edu/flaent/article/view/75622/73280

Zapien, G., J. Hendrichs, P. Liedo, and A. Cisneros. 1983. Comparative mating behaviour of wild and mass-reared sterile medfly Ceratitis capitata (Wied.) on a field cage host tree - II. Female mate choice, pp. 397-409. In R. Cavalloro (ed.), Proceedings, Symposium: Fruit Flies of Economic Importance. CEC/IOBC International Symposium, 16-19 November 1982, Athens, Greece. A. A. Balkema, Rotterdam, The Netherlands.

Zervas, G. A., and A. P. Economopoulos. 1982. Mating frequency in caged populations of wild and artificially reared (normal or gamma-sterilized) olive fruit flies. Environmental Entomology 11: 1720. https://doi.org/10.1093/ee/11.1.17

Zhang, K., H. Fu, S. Zhu, Z. Li, Q. F. Weng, and M. Y. Hu. 2016. Influence of gamma-irradiation on flight ability and dispersal of Conopomorpha sinensis (Lepidoptera: Gracillariidae). Florida Entomologist 99(Special Issue 1): 79-86. http://journals.fcla.edu/flaent/article/view/88489/84957

Zygouridis, N. E., Y. Argov, E. Nemny-Lavy, A. A. Augustinos, D. Nestel, and K. D. Mathiopoulos. 2014. Genetic changes during laboratory domestication of an olive fly SIT strain. Journal of Applied Entomology 138(Special Issue): 423-432. https://doi.org/10.1111/jen.12042 